\title{
Strengthening the Foundations: An Introduction to the Role of Conceptual Metaphor Theory in Art Therapy
}

\author{
Amelia Thomley, LPC, MAAT*; Adam Safron, PhD ${ }^{1,2,3}$ \\ ${ }^{1}$ Department of Psychiatry and Behavioral Sciences, Johns Hopkins University School of Medicine \\ ${ }^{2}$ Kinsey Institute, Indiana University \\ ${ }^{3}$ Cognitive Science Program, Indiana University \\ *Corresponding author: ameliathomley@gmail.com
}

\begin{abstract}
This paper offers an introduction to conceptual metaphor theory (CMT), rooted in the cognitive linguistics field of study, and its application to art therapy theory and practice. Utilizing comics as a form of further elaboration and explanation, this manuscript is divided into four main sections: 1) an overview of current theories of conceptual metaphor, 2) a review of metaphor in art therapy, 3) an introduction to metaphor in comics, and 4) a discussion of how CMT applies to art therapy practice. Additionally, the appendix includes an encapsulation of these ideas in the form of a comic. CMT proposes that metaphor is one of the main ways that humans are able to have abstract thought, and argues that metaphors often 1) work from the concrete to the abstract, 2) are based in bodily experience, and 3) build on each other over time, forming interconnected conceptual systems. Simultaneously, the field of art therapy utilizes metaphor in the understanding of both the process and product of artmaking. The authors put forth that the work being done in cognitive linguistics can enhance and support the work being done in art therapy, and that CMT will further our understanding of art therapy pedagogy and practice.
\end{abstract}

Keywords: conceptual metaphor, metaphor, art therapy, cognitive linguistics, embodiment, cognitive science 


\section{Table of Contents}

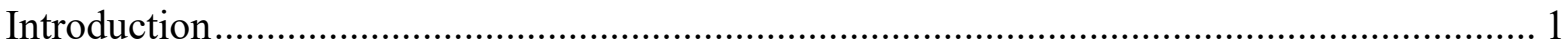

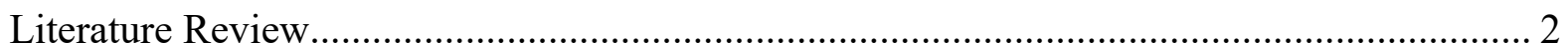

The Theory of Conceptual Metaphor............................................................................... 2

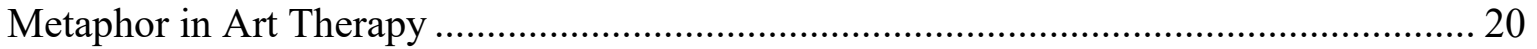

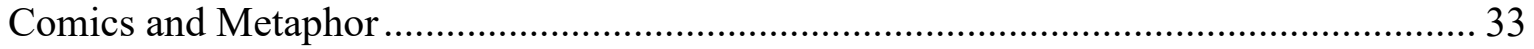

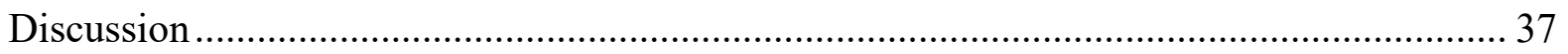

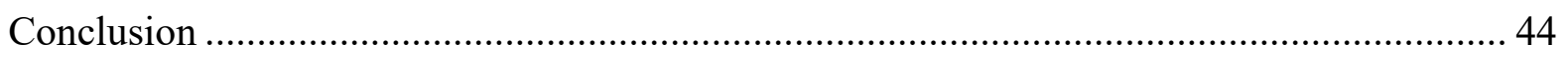

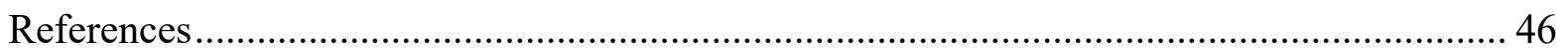

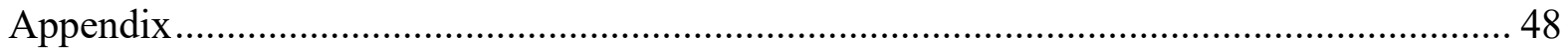

List of Tables and Figures

Table 1. Excerpt from primary metaphor list in Grady ................................................... 6

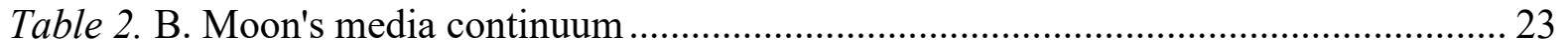

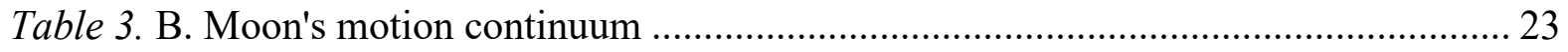

Figure 1. "The Dream of My Blue Evening Dress" ...................................................... 28

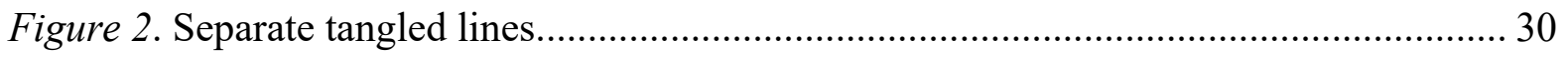

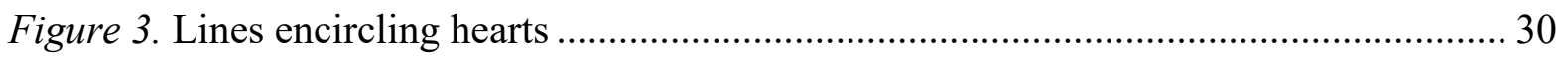

Figure 4. Encircled and connected hearts............................................................... 31

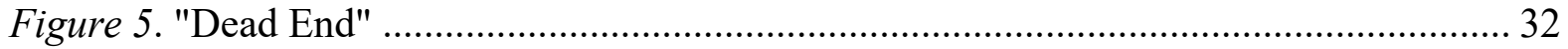




\section{Introduction}

How does art therapy heal? As art therapists, we see the powerful results of our work on a day-to-day basis, and the changes we see in the people we work with contribute to a deep feeling of knowing that art makes a difference. The connection between art and healing is likely one of the most commonly expressed sentiments among art therapists. While evidence is slowly amassing to show the effects of our work, there is still a limited understanding of why art therapy is effective. In investigating the therapeutic efficacy of art therapy, we propose that a particularly valuable converging line of evidence can be found in an in-depth examination of metaphor and its importance in human cognition. Within the field of cognitive science, the study of conceptual metaphor has existed for over 30 years.

Throughout this time, the field has been contributing theories and evidence for metaphor being one of the essential bases of cognition. In this manuscript, we provide an introduction to conceptual metaphor theory (CMT) and draw connections to art therapy literature, in an attempt to both add support to the current beliefs and practices of art therapy, and demonstrate that CMT can enhance art therapists' understanding of their work. With further grounding in the pervasiveness and importance of metaphor, the field of art therapy can deepen its understanding of the use of metaphor in practice, and further its influence on other fields of study. The work that has been done in cognitive linguistics to study metaphor can be used to further clarify what art therapy does and can do for clients and communities.

In addition to an in-depth scholarship review and theoretical analysis, included in the appendix to this manuscript is an exploration of the material in comic format. This comic utilizes both linguistic and visual metaphor to further understanding of conceptual metaphor theory and how it relates to art therapy, and itself becomes an illustration of the ways that 
images can communicate information. The extensive scholarship review and comic illustration of the theories presented provide a basis for additional strengthening of the foundation of the field of art therapy.

\section{Literature Review}

\section{The Theory of Conceptual Metaphor}

Metaphors are often thought of as being poetic turns of phrase, elaborating on a concept in a creative way that changes the perception of that concept. Lakoff and Johnson (L\&J) (1980) put forth their conceptual metaphor theory (CMT) in their seminal work, Metaphors We Live By. Here, they explain that metaphors are embedded deeply into everyday language in ways that are often overlooked. The pervasiveness of metaphor in language implies that humans use metaphors as part of their natural thinking process, which in turn implies that metaphorical thinking is one of the principle ways that humans come to understand the world.

For instance, a popular song says, “you are my sunshine, my only sunshine.” These lyrics connect the idea of a person with the mental imagery of basking in sunshine, allowing the listener to understand the object of the song not only as a great love, but also as the thing that brings light, warmth, and sustenance to the singer. With the inclusion of the word "only," the song even goes as far as to imply that this love provides even more sustenance than the literal sun. This view of metaphor imagines it as being an enlightening but limited tool that is only used sparingly in language. As well, this view assumes that the use of metaphor is mainly the purview of artists and poets, and not the stuff of everyday speech and thought. This section will outline an alternative view that states that metaphor is pervasive throughout language, and is thus embedded into our thought structure. In this view, metaphor 
is used both consciously and unconsciously to connect concepts and understand complex ideas.

Metaphor is most basically described as understanding one thing in terms of another thing. These "things" could be objects, people, physical sensations, particular concepts, or an entire system of concepts. The type of metaphor that $\mathrm{L} \& \mathrm{~J}$ describe underscores that one concept, or system of concepts, is being understood in terms of another. They theorize that we use more concrete concepts to understand abstract concepts, and that some metaphors are so basic that they provide the building blocks for thought. In developing CMT, one of the first systems of metaphor that Lakoff and his students discovered was LOVE IS A JOURNEY', which compares the concept of a journey to the concept of love, specifically a love relationship (Association of Psychological Science, 2015). Kovecses (2010) lays out these examples of LOVE IS A JOURNEY found in everyday speech (p.33):

Look how far we've come.

We'll just have to go our separate ways.

I don't think this relationship is going anywhere.

We're stuck.

It's been a long, bumpy road.

Looking at these examples in one place, one can begin to understand the way that metaphor is commonly used. Here, there seems to be an overall conceptualization of a love relationship as being on a trajectory. When someone says, "I don't think this relationship is going anywhere," they most likely are not consciously thinking about how their overall conception

\footnotetext{
${ }^{1}$ It is customary practice in cognitive linguistics to denote systems of metaphor by writing them in smaller, all caps text, as seen here with LOVE IS A JOURNEY. It is also customary to use italics to denote metaphorical words and phrases in specific examples of these metaphoric systems.
} 
of love is related to their conception of a journey. And yet, this statement implies an underlying belief that movement in any direction is necessary - if love is a journey, then for love to exist, there must be movement. If one is no longer moving, then the journey, and the love, has ended. Different systems of metaphors can exist for the same concept. Other understandings of love include LOVE IS MADNESS ("they are crazy for each other") and LOVE IS HEALTH (“our love is strong.") (Lakoff \& Johnson, 1980). Each system provides a slightly different understanding of love. LOVE IS MADNESS, for instance, makes it seem as though love is uncontrollable, while LOVE IS HEALTH implies that love may grow strong if loving is practiced, or exercised. No single metaphorical system can completely explain the ephemeral idea of love, thus it is the combination of these multiple points of view that allow us to conceptualize love in all of its multifaceted and dynamic qualities (Kovecses, 2010). There may be points at which the idea of love seems more like madness, and points at which it seems more like health.

Each of these metaphorical systems describing love work from the concrete to the abstract. This is how metaphorical understanding generally works - a commonly known object, body state, or phenomenon is used to make sense of emotions, complex ideas, and otherwise unobservable concepts. In the case of LOVE IS A JOURNEY, the concept of a journey, being in the process of moving from one place to another, is used to better understand the concept of love, a common feeling with no tangible elements. The terminology used to label these two aspects of a metaphor are the source and the target (Gentner, 1983; Kovecses, 2010). The source concept in a metaphor is the domain of knowledge that is being pulled from to better understand the target concept. In this example, JOURNEY is the source concept and LOVE is the target. 
Primary metaphors. Primary metaphors are the metaphors that are most basic and integral to human experience, and thus may be the most powerful (Grady, 2007). Primary metaphors "map fundamental perceptual concepts onto equally fundamental but not directly perceptual ones.” (p. 192). In his exhaustive dissertation on the subject, Grady (1997) elaborates that fundamental perceptual concepts are experiences that are integral to human existence, and are those that we directly perceive. Perception refers to what we are able to experience through the senses, what we are able to hear, touch, taste, see, and smell. These kinds of concepts would include such concepts as heaviness, lightness, heat, cold, hunger, up and down. Through experience, these concepts become associated with other concepts that are equally fundamental, but not as easily understood. Grady lists such examples as difficulty, desire, happiness, and similarity as examples of target concepts. To best illustrate the kinds of connections that Grady considers, we have included an approximation of a portion of a table included in his dissertation (Table 1). Note that the source terms are all immediately perceivable, direct experiences, while target terms are equally fundamental aspects of human experience, but are not directly accessed with perception. The term "grounding" is a term often used in the study of metaphor, and refers to the potential reasoning behind the existence of the metaphor. In this case, each metaphorical grounding has to do with direct experience. 


$\begin{array}{llll}\begin{array}{llll}\text { Source } \\ \text { HEAVINESS }\end{array} & \rightarrow & \begin{array}{l}\text { Target } \\ \text { DIFFICULTY }\end{array} & \begin{array}{l}\text { Grounding } \\ \text { (Difficulty of lifting heavy } \\ \text { objects) }\end{array} \\ \text { HUNGER } & \rightarrow & \text { DESIRE } & \begin{array}{l}\text { (Correlation between } \\ \text { physical sensation and } \\ \text { focus on finding food) }\end{array} \\ \text { ITCH } & \rightarrow & \text { COMPULSION TO ACT } & \begin{array}{l}\text { (Correlation between } \\ \text { physical sensation and } \\ \text { compulsion to scratch) }\end{array} \\ \text { BRIGHTNESS } & \rightarrow & \text { HAPPINESS } & \begin{array}{l}\text { (Correlation between } \\ \text { bright light and safety } \\ \text { warmth, etc) }\end{array}\end{array}$

Table 1. Excerpt from primary metaphor list in Grady

Grady asserts that complex metaphors can be broken down into their primary components, and that this process of breaking down leads to a better understanding of the way that metaphors work. To illustrate this, he examines the metaphor system IDEAS ARE FOOD, first put forth in L\&J (1980). Examples of this metaphor, taken from Grady's dissertation, include:

Let me stew over that for awhile.

I just can't swallow that claim.

There are too many facts here to digest them all.

What he said left a bad taste in my mouth.

Grady notes that though these metaphors do correspond to a connection between ideas/communication and food, the mapping does not systematically align with experience. For instance, one might say that they need time to digest something before they can swallow it. However, this order of events does not correspond with the order that one would do these actions in real life. Thus the metaphor system IDEAS ARE FOOD seems to be inconsistent. 
Grady posits that there must be different motivations, or different underlying primary metaphors, to account for this inconsistency in phrasing.

In examining the act of swallowing, Grady (1997) correlates swallowing with acceptance, noting that we are only made acutely aware of the action of swallowing when something is literally hard to swallow. In such cases, we make a conscious choice to accept a foreign substance into our bodies. SWALLOWING IS ACCEPTANCE is a primary metaphor because it pairs a concrete physical experience with an equally fundamental, yet nonperceptual concept. A sentence like "his grades for that semester were a bitter pill to swallow," then becomes grounded more specifically by SWALLOWING IS ACCEPTANCE. Separately, digestion seems to have many different potential primary groundings, among them ANALYZATING IS TAKING APART and LEARNING IS ABSORPTION. Thus, inconsistencies within the general metaphorical system IDEAS ARE FOOD can be resolved when that metaphorical system is further broken down into its primary metaphor sources. This deep analysis of language serves to demonstrate the way that complex thoughts and concepts are grounded in more basic associations, which themselves are based in human experience.

Experiential basis of metaphor and embodiment. L\&J (1980) make the claim that, "In actuality we feel that no metaphor can ever be comprehended or even adequately represented independently of its experiential basis.” (p.19). Furthering this claim, L\&J describe three types of metaphor systems that deal directly with human experience in the body: orientational, ontological, and structural. Orientational metaphors get their basis from the position of the body in space, or spatial understandings as they relate to the body. This could refer to the direction of the body, vertical or horizontal positioning of the body, or being inside or outside. This could also refer to something being central or peripheral, deep 
or shallow. Certain orientations can come to be associated with certain corresponding events or concepts. These kinds of associations are also often primary metaphors. For instance, that our bodies are usually upright when we are healthy, and crumpled, or low to the ground when we are sick, may lead to a general association with "good" being equal to "up," getting us phrases like "things are looking up." (p.16). Because of common human experience, upward orientations are often connected with positive concepts, while downward orientations are often connected with negative concepts. Other examples given by L\&J (1980), quoted from p.15, include:

HAPPY IS UP; SAD IS DOWN

I'm feeling up. That boosted my spirits. My spirits rose.

I'm feeling down. I'm depressed. He's really low these days.

CONSCIOUS IS UP; UNCONSCIOUS IS DOWN

Get up. Wake up. He rises early in the morning.

He fell asleep. He sank into a coma.

As these examples illustrate, CMT involves the idea that we utilize information gathered from our inner and outer bodily experiences, sometimes consciously, and sometimes unconsciously. In the case of HAPPY IS UP; SAD IS DOWN, these connections have been created through a combination of: 1) individual experience of noting others being vibrant and upright when happy, and slow and hunched over when sad 2) individual inner experience of having energy with happiness and slothfulness with sadness and 3) an accumulation of cultural knowledge that reinforces and communicates these connections. As we experience the world and ourselves, many different phenomena arise that we must somehow make sense of. Kovecses (2010) notes that perhaps orientational metaphors would be better described as "coherence" metaphors, in that rather than being focused completely on orientation, they 
group various phenomena together to form a coherent structure of ideas. The above mentioned example of upwards orientation often being equated with the positive would be an instance of grouping together many learned systems of metaphors (i.e. HAPPY IS UP; CONSCIOUS IS UP) to create a coherent structure.

Ontological metaphors allow us to give boundaries to otherwise unbounded entities, states of being, events, or ideas. Though they help to contain phenomena, they remain somewhat vague in the information they can give. Koveceses (2010) writes, "what this means is that we conceive of our experiences in terms of objects, substances, and containers, in general, without specifying exactly what kind of object, substance, or container is meant." (p. 89). For example, L\&J (1980) offer a breakdown of instances where we conceptualize the mind as a brittle object. We get phrases like:

Her ego is very fragile.

She is easily crushed.

The experience shattered him.

His mind snapped.

This metaphor, THE MIND IS A BRITTLE OBJECT gives physical limits to the abstract idea of the mind. Envisioning the mind as a brittle object allows the mind to have certain physical properties, like being easily broken and needing careful handling. Human experience with brittle objects lets us apply these properties to the mind. Like orientational metaphors, ontological metaphors have an experiential basis. Additionally, we can also understand phenomena in terms of a person, in a version of ontological metaphor called personification. An example of personification would be "life has cheated me." (p.33, Lakoff \& Johnson, 
1980). In this example, "life" takes on a human ability to perform an action, in this case, cheating. Here, the concept of life is understood in terms of having human attributes.

Structural metaphors include the kind of metaphors that are most easily recognizable as metaphors. Structural metaphors involve source concepts that include a wide array of predicates (things that make up the structure of the concept) that can be matched up with the target concept, giving many opportunities for new meanings. They very label of "structure" is in-and-of itself a metaphor, with the term giving rise to the idea of many parts aligning in order to create a sound, stable framework. While ontological and orientational metaphors are described as being somewhat vague or generalized, structural metaphors have the ability to contribute more specific knowledge about the target concept (Kovecses, 2010). For instance, HAPPY IS UP does not explain much about any specific concept, rather it organizes a system of correlated events under one domain, categorizing uprightness as generally being related to happiness. On the other hand, LOVE IS A JOURNEY offers many different and specific inferences about love, namely that it is a process, it moves and changes, and that it has a point where it begins and ends. Other, more unique kinds of metaphors would also be considered structural metaphors. In his song, “I’m on Fire,” Bruce Springsteen (1984, track 6) sings about a "freight train running through the middle of my head," which creates a specific image. Experience with literal freight trains makes this metaphor salient, and helps the listener to understand that the thoughts Springsteen is having feel urgent, heavy, unstoppable, and noisy.

Gibbs (1996) explains that the accumulation of information from the senses, perception, and internal body states can "give rise to the development of an experiential gestalt, called an image schema." (p.316) (emphasis in original). An image schema 
incorporates multiple sources of information to form an understanding of a concept. To further explain, we will utilize a primary metaphor mentioned above in Table 1: HEAVINESS IS DIFFICULTY. Examples of this metaphor in language would be:

That's a heavy subject.

The thought of her weighs heavy on his mind.

She had to drag him along.

He was doing a lot of the heavy lifting in their class presentation.

Theoretically, these sentences are understood at least in part because the terms related to heaviness are activating an image schema of interacting with a heavy object (Gibbs, 2006). This image schema is built up, solidified, and elaborated on throughout a person's development. Hypothetically, most people have experience with trying to lift an object and finding that they cannot lift it, creating a sense of frustration. Within the sentence "that's a heavy subject," the word "heavy" is not merely a synonym for "difficult." Instead, the argument is that the "subject" is understood conceptually as being heavy, and that readers of that sentence may be literally imagining that subject as having weight. Gibbs (2006) contends that these kinds of examples could be elaborated on to apply to many other systems of metaphor. Given that a large amount of complex metaphors are thought to be based in primary metaphor, and that primary metaphors are based in experience, it would seem that much of language is based around human embodiment.

Various studies have hinted at the connection between metaphor formation and embodiment by showing a connection between language, thought processes, and action. Zhong and Liljenquist (2006) examined the embodied connection between moral purity and cleanliness in a series of short studies. Inspired by noting the ritual of cleansing that exists in 
multiple prominent religions, they were curious about whether physical cleansing was related to internal feelings of moral rightness. This metaphor could be referred to as CLEANLINESS IS MORAL PURITY. In the first study, subjects were found to be more likely to think of words related to cleanliness after having been asked to reflect on an "unethical deed" as opposed to an ethical one. A later study in the same publication looked at the behavior that would result from these unethical thoughts. Participants that were asked to reflect on an unethical deed were more likely to choose the gift of an antiseptic wipe over the gift of a pencil (gifts which had been previously shown to be of equal value to a control group), implying that the desire to self-cleanse was stronger after having had unethical thoughts. Further, another study showed that those prompted to think of an unethical deed were less likely to volunteer to help others with research if they had used an antiseptic wipe beforehand, having already cleansed themselves after their unethical thoughts. Those that had used the antiseptic wipe also reported less morality-related emotions (including disgust, shame, and regret). These results support the idea that the metaphor CLEANLINESS IS MORAL PURITY involves real-world changes in feelings and behavior, such that physical cleansing may (at least temporarily) remove more anxieties.

Also examining the connection between experience and metaphor, Tseng et al. (2004) found that activation of a conventional metaphor's experiential source could prime verbal use of the corresponding target. In this study, they looked at the sayings "searching for happiness" and "full of joy." They found that participants who were currently in the act of searching were more likely to refer to a face as showing "happiness," while those currently in the act of drinking a beverage (thus holding a container "full" of liquid) were more likely to refer to that same face as showing "joy." 
Elsewhere, thinking about future or past events was correlated with leaning forward or backward, respectively, showing experiential connection to the idea of moving backwards or forwards in time (Miles, Nind, \& Macrae, 2010); holding a warm beverage was correlated with judging a stranger to be more kind and generous, in other words, that they had a "warm" personality (Williams \& Bargh, 2008); and the touching of heavy, rough and hard objects influenced changes in perception of the seriousness, harmony, and strictness of various respective situations (Ackerman, Christopher, Nocera, \& Bargh, 2010).

The above examples focus strongly on individual experience, but embodiment's effect on understanding is not relegated to within the individual. Sweetser (1998) notes, Our cognition is not only embodied, but physically and socially interactive with other embodied cognitive beings, and a rich area of cognitive activity is our understanding of social relationships; linguistic communication is constantly physically and socially situated in a broader frame of social and physical interaction, activities, and environment. (p. 1).

Essentially, the shared experience of being in a body in the world is what allows humans to communicate with each other. Above, we have seen some of the ways that being in a body affects metaphorical connections in both language and action. In communicating, gestural motions during speech have been associated with enhancing understanding of language and concepts, both for the speaker/gesturer and the viewer (Sweetser, 2006). These gestures have been seen to be related to conceptual metaphor systems, such as ABSTRACT IS UP; CONCRETE IS DOWN, as when a speaker continually gestured upwards to indicate abstract ideas and downwards to indicate more concrete ideas. Sweetser (1998) argues that concrete, visible gestural motions enhance comprehension of abstract ideas, just as CMT argues that concrete 
source domains enhance comprehension of more abstract target concepts. Gesture is a source of information that both reflects internal processing of concepts and communicates meaning to others.

How metaphors are created. When a source concept is used to better understand a target concept, this process is understood to be a kind of mapping (Kovecses, 2010). Properties that make up the source concept are mapped onto the target concept. However, it is not common for all of the source properties to be mapped onto a target concept. Kovecses writes that there is a process of highlighting and hiding that occurs, where the source concept elevates some aspects of the target concept and leaves the rest. For instance, LOVE IS MADNESS highlights the uncontrollable aspects of love, and leaves out other aspects such as maintenance and choice.

Bowdle and Gentner (2005) describe how this might work in their article, The Career of Metaphor. The authors describe Structure Mapping Theory, which looks at metaphor as an alignment process between two representations that creates the most structurally consistent match. Salient features from both the target and the base can be thought of as aligning with each other. For instance, Bowdle and Gentner offer the example of two instances of metaphor: "Youth is a snowflake" and "a child is a snowflake" (p.197). In the first, the brevity of both "youth" and "snowflake" are highlighted, resulting in the thought that youth is temporary, quickly melting away. In the second, the uniqueness of "child" and "snowflake" are highlighted, resulting in the thought that children are special, one-of-a-kind configurations. Though these metaphors utilize the same source domain, the interpretation of them is different because of the differing ways that this source domain maps onto the target concept. 
Important in Bowdle and Gentner is the notion that connections are made between the source and the target, and it is not merely that information from the source is mapped onto the target indiscriminately. It is unlikely that a child is a snowflake will lead to the thought that a child is symmetrical, or that a child is frozen. The aspects of the source concept that map onto the target will be similar to aspects of the target concept. However, there is an element to this that makes the process more than just finding similarities between the two concepts. The mapping is still directional, going from source to target and not the other way around. Grady (2007) notes that directionality is one of the essential aspects of conceptual metaphor theory. Were a similarity between concepts the only necessary prerequisite to metaphor creation, one would expect that metaphors would work both ways. But a snowflake is a child does not seem to make much sense. Or, to reverse a greater system of metaphors, A JOURNEY IS LOVE also does not seem to be accurate, and neither do we see examples of that in language. Though some metaphors are indeed reversible, it is often the case that they are not. This directionality supports one of the main tenets of conceptual metaphor theory - that the basis of much of human understanding of the world is the result of using one concept to understand another, not merely that certain concepts have similarities to each other.

Instead of similarity, many systems of metaphors instead have a correlational relationship, which grows out of our experiences in the world (Kovecses, 2010). For instance, there is no appreciable similarity between the concept of "more" and the concept of "up.” Rather, the understanding that MORE IS UP has come about because of repeated exposure to these two concepts being related in human experience. Kovecses points to liquid rising in a container as being one example of this. Another example might be creating a pile of sand at the beach. A young child notices that as he adds more sand to his pile, the pile 
grows larger and taller, expanding upwards. These kinds of simple experiences are reinforced over and over, creating a lasting pattern, a foundation from which to understand the world.

Evolution of metaphor. Bowdle and Gentner (2005) describe how metaphoric bases can grow in meaning and become polysemous, or have multiple meanings. Novel metaphors begin as comparisons between two representations. For instance, take the base term "monster" and the target "mother-in-law." One might say, "my mother-in-law is a monster," implying that the mother-in-law is terrifying and out of control by making a comparison to a such a creature. If a base term is used repeatedly over time with different targets and found to accurately highlight appropriate schemas of meaning, this base term may go on to become polysemous. Using our "monster" base, we could go on to say, "my thesis is a monster; his guilt is a monster; or, the threat of conflict with Russia is a monster." With time, the word “monster" comes to mean not just a literal beast, but also comes to represent an overall category of a thing that is large, frightening, and unpredictable. As "monster" becomes polysemous, it becomes what is known as a conventional metaphor.

LOVE IS A JOURNEY is what L\&J (1980) would call a conventional metaphor, one that is often used, and barely noticed, in everyday language. Conventional metaphors often get the job done, expressing all that needs to be communicated about a particular idea. However, conventional metaphors are not always enough. Unconventional metaphors are systems of metaphor that stand out, thanks to their novelty. These metaphors have the ability to highlight aspects of a target that are not normally highlighted. To illustrate this, L\&J developed a novel metaphor LOVE IS A COLLABORATIVE WORK OF ART. Viewing love in this way gives rise to a series of inferences, called "entailments," about its nature (p.140):

Love is work. 
Love requires cooperation.

Love requires dedication.

Love requires compromise.

Love regularly brings frustration.

Love creates a reality.

These entailments reflect that the process of creating a collaborative work of art highlights aspects of love that other metaphorical systems might not. L\&J note that these entailments particularly highlight aspects of love that are active.

As metaphors can grow, they can also die. Bowdle and Gentner (2005) describe the end of a metaphor's career as being when the base term becomes completely detached from its original literal meaning. The offer the example of a "blockbuster," which originally was a reference to a bomb that could destroy entire city blocks. Today, we use the term to refer to an extremely popular movie, without knowledge of its origins. The word is no longer metaphorical, but has become literal again, with a different meaning. It should be noted, however, that CMT often deals with metaphorical statements that some might understand as "dead" but actually are active in affecting thought (Gibbs, 2011). Gibbs gives the example of the term, "stay the course." (p.532). CMT would argue that this terminology, though commonly heard, still activates an image in the mind of staying on track and going in the right direction.

Metaphor and the unconscious. Conceptual metaphor theory deals with metaphorical thinking that is often surprisingly mundane and conventional, illustrating that metaphor pervades everyday thought in ways that are difficult to consciously discern. Thibodeau and Boroditsky (2011) demonstrated that metaphoric systems can influence the 
way that we think when they examined subjects' responses to differing framings of crime. The authors framed a crime problem as either a "beast" or a "virus" and found that those exposed to the "beast" framing were more likely to suggest solutions that were focused on increasing law enforcement (as if to combat a beast), while those exposed to the "virus" framing were more likely to suggest solutions that were focused on social reform to get at the root causes (as if treating a disease). Moreover, participants in the study were not likely to be aware that the metaphor is what had influenced their decision-making process, implying that the influence of metaphors can be unnoticeable.

Lakoff (1992) applied the theory of conceptual metaphor to dream analysis, tying it explicitly to the idea of the unconscious. Unconsciousness as it is understood in the field of cognitive linguistics is different from Freud's idea of the unconscious. While Freud saw unconscious thoughts as being repressed and capable of being brought forth into conscious awareness, Lakoff understands them as being part of implicit consciousness. The majority of metaphors could be seen as being a part of implicit memory, which allows humans to complete tasks with the minimum amount of effort expended thinking about the problem (Schacter, 1987). The same system of memory that enables people to tie their shoes without agonizing over each step is the system that houses conventional metaphor. As Lakoff explains, though one may be able to notice that their linguistic patterns demonstrate that their understanding of love is partly based around their understanding of a journey, it would be impossible to hold these associations in constant conscious awareness.

Emotion and metaphor. Emotions have a bodily, and thus experiential, component, which is felt in similar ways across cultures (Nummenmaa, Glerean, Hari, \& Hietanen, 2013). The abstractness of emotions, combined with their embodied nature, makes them ripe 
for metaphorical ways of understanding and communicating them. For instance, anger is often described as being related to heat. To give a better idea, Kovecses (2010) outlines metaphors that relate to the ANGER IS HEAT conceptual system:

Boil with anger

Make one's blood boil

Be stewing

Be seething

Be burned up

Breathe fire

Inflammatory remarks

These examples demonstrate how the ANGER IS HEAT conceptual system is integrated into everyday language and expressions, and how the feeling of heat is used to help comprehend the abstract concept of anger. Other metaphorical systems interacting with this are ANGER IS A HOT FLUID and ANGER IS FIRE.

By and large, emotions may be said to have a master metaphor that governs most understanding of emotion, namely EMOTIONS ARE FORCES (Kovecses, 2008). Though other concepts can be thought of in terms of forces, emotions as a category are overwhelmingly thought of as forces acting upon a person. This kind of force could be as an opponent, a force of nature, or a physical force (i.e. magnetic force). While this master metaphor can be seen cross-culturally, it is at a general level of understanding. Emotion metaphors, and metaphors on the whole, exist both at general, more universal, levels as well as at culturally specific levels, effectively creating a hierarchy of metaphor. 
Cultural variation in metaphor. Writing about cultural variation in emotional metaphor, Kovecses (2010) explains that general-level emotional metaphors are often relatively universal, while more intricate emotional metaphors are often culturally specific. THE ANGRY PERSON IS A PRESSURIZED CONTAINER is an example of a generalized metaphor that exists nearly universally. However, elaborations on this concept can be specific to different languages and countries. In Japan, there is an idea of anger being in the belly, or the "hara." Thus, there are metaphorical systems in Japan that revolve around this concept of belly-anger. Meanwhile, in the United States, there is no such widespread metaphorical understanding of that nature. Further, Kovecses argues that metaphorical systems can become so specific as to relate to the life of just one person. Using Hemingway as an example, Kovecses points to the richness of his metaphors relating bullfighting to masculinity and life circumstances, metaphors which may not have arisen if Hemingway had not been personally invested in that sport.

\section{Metaphor in Art Therapy}

One of the foundations of art therapy is a belief that both the process and the product of creation are representative in some way of the artist. The process of creating artwork is seen as a way of knowing, examining and communicating the self (Allen, 1995; B. Moon, 1992; Kramer, 2000; McNiff, 1992; and many others). The finished artistic product is similarly seen as an expression of the history, beliefs, personality, or state of mind of the creator (C. Moon, 2002; Martin, 1997; Naumburg, 1987; and many others). Kramer (2000) asserted that focus on the process of artmaking and the artistic product were not dichotomous in nature. Profound works of art are the result of a valuable process of making; both the process and product inform 
each other. In this review, we do not wish to promote a dichotomy between the two ideas, or to privilege one over the other. However, the differences between process and product provide a useful way to examine metaphor as it arises in art therapy.

What follows is a delineation of the various ways that art therapists have understood metaphor in both the process and product of art-making.

Metaphors in art therapy: Process. The process of art-making necessarily involves interaction with materials, and it is the addition of materials to the therapeutic setting that differentiates art therapy from other therapeutic professions. Working with physical materials means activation of the senses. Don Seiden (2001) writes, "Our sensations are the doorway to understanding one another. Sensations are also the doorway to art expression, and art may very well be the ultimate form of communication because it makes visible the invisible." (p.15). Art is physical, it has a weight, a texture, a color, and it is precisely because it is physical that it has the potential to be such a powerful communicator. Different kinds of materials give rise to different kinds of sensations for the artist, and thus material choice may be related to different kinds of feelings. In his book, Mind Over Matter, Seiden (2001) lists drawing, painting, sculpture, fibers, and multimedia materials and briefly explores their properties. For instance, paper may be "torn, cut, burned, crushed, and otherwise easily transformed." (p.32). Paper may also be deceptive in that it can appear to be merely a flat surface. To view it as anything else could indicate a certain amount of either expertise or risk-taking on the part of the artist. Even paper, a mundane-seeming kind of material, has particular properties that lend itself to certain kinds of manipulation and interaction. The properties inherent in the paper interact in a bidirectional way with the artist's inner state at 
the time of making the art piece. Given this, Seiden thus believes that the process of working with a material becomes metaphorical for the artist herself.

In explaining her understanding of the creative process, Rubin (1984) writes that it is held within a continuum of freedom and order. While elements of both freedom and order are important, neither complete freedom nor complete orderliness are optimal for creative expression. In order to bring about a successful creative experience for clients, art therapists should be able to provide them with the optimal combination of freedom and order. However, when left to their own devices, clients may also attempt to find the optimal combination for themselves. Rubin (1984) noted that the children with schizophrenia who she worked with would often keep themselves away from fluid materials when given free reign over which materials to choose. She connects this behavior to their psychological state, hypothesizing that their tendency towards overly fluid self-understanding influenced them to gravitate towards the higher structure of harder materials.

The dynamic relationship between freedom and order can be seen in the combination of continuums that B. Moon (1992) outlines in his art therapy assessment procedure, reproduced in Table 2 and 3 below. Table 2 displays a continuum of material qualities, while Table 3 lays out the movements that a client might exhibit during the assessment, with or without using the materials.

\section{MEDIA}

\begin{tabular}{|l|r|}
\hline $\begin{array}{l}\text { Resistive } \\
\text { (charcoal) }\end{array}$ & $\begin{array}{r}\text { Pliable } \\
\text { (Play-doh) }\end{array}$ \\
\hline $\begin{array}{l}\text { Controllable } \\
\text { (Pencils) }\end{array}$ & $\begin{array}{r}\text { Fluid } \\
\text { (water colors) }\end{array}$ \\
\hline
\end{tabular}




\begin{tabular}{|l|r|}
\hline $\begin{array}{l}\text { Familiar } \\
\text { (crayons) }\end{array}$ & $\begin{array}{r}\text { Unfamiliar } \\
\text { (oil pastels) }\end{array}$ \\
\hline $\begin{array}{l}\text { Meticulous-fine motor } \\
\text { (pen and ink) } \\
\text { (fine brush) }\end{array}$ & $\begin{array}{r}\text { Gross motor } \\
\text { (tempera paint) }\end{array}$ \\
\hline
\end{tabular}

Table 2. B. Moon's media continuum

\section{MOTION}

\begin{tabular}{|l|r|}
\hline Tight/constricted & Loose/fluid \\
\hline Rhythmic & Spasmodic \\
\hline Fine & Gross \\
\hline Aggressive & Passive \\
\hline
\end{tabular}

Table 3. B. Moon's motion continuum

While Moon assesses many other components of client behavior and affect during the session, the interaction of the patient with the materials plays a significant role in his notes. For instance, in a case example, when a patient chooses to use a pencil from a myriad of available options, Moon hypothesizes that the patient may have chosen this material for its easily controllable quality, ability to be erased, familiarity, and lack of spontaneity. Moon then aligns this material usage with observation of the patient's constricted motion to make inferences about his "inhibited"(p.144) internal state. The material and the behavior with the material become a metaphor that the art therapist uses to understand the client's psychological processes.

Art therapy assessments are often where understanding of a material's effect on clients is most clearly stated. Many assessments include instructions to take note of the way that the client is interacting with the materials provided. For instance, Landgarten's (1993) collage assessment hypothesizes a connection between the way a client selects and pastes down magazine photos, and their cognitive/behavioral style. The amount of glue, the level of messiness, the placement, and the amount of time 
taken with the materials are all elements that factor into the assessment, giving more information about the client.

While the client may have control over the choice of material, it is also possible that the quality of the material may end up changing the client's behavior in unpredictable ways. Rubin (1984) believes that it is more often fluid or messy materials that can lead to emotional flooding, or "messy" emotional states. She mentions finger-paint and clay, writing, "their similarity to body products may have exerted a strong regressive pull, stimulating memories and feelings associated with early childhood, as well as impulses." (p.68). In this case, it is the client making an unconscious metaphorical connection to past associations. This kind of a response to a material is referred to as regression, but Rubin is clear that regression does not merely signify a breaking down of self-regulation. Regression can also be a natural part of the creative and therapeutic process, signaling a transformation or spurt of growth, a kind of necessary release in order to allow for more control later. In working with children, Rubin advises adults to become comfortable with regression, even making space to allow it to happen, in the hopes that this way of behaving and using materials is a signal of positive exploration and increasing control.

Sholt and Gavron's (2006) review of the use of clay in art therapy notes the many different qualities of clay as a material, including the potential for clay to facilitate regression. The authors also note the material's facile reaction to touch, ability for transformation, and that it may form sculptures that have inner and outer surfaces. Working with clay could be an opportunity to release pent up energy, as it is a material that can be beaten, thrown around, and squished. The authors describe various ways that regression has been seen with clay, including the use of clay to depict food, feces, and sexual organs. At a 
more basic level, clay could invite regression by nature of its hands-on tactile quality, providing an intense experience that immerses the client in sensation. Simultaneously, clay can be treated preciously in the act of re-creating objects and figures that hold value. The authors also connect clay to a long history of human expression of desire for utility and sacredness.

Seiden (2001) refers to past associations with materials writing, “...each of us has had a natural attraction to certain materials and objects. As artists, we have had experiences with substances that created strong impressions at early ages. ... we all have memories of 'things' which seemed almost an extension of ourselves." (p.21). It stands to reason that these personal past associations could also in part be influenced by built up cultural associations with material that have been passed down through time. C. Moon (2010) hints at this idea when she describes use of art materials as a "tangible vocabulary." (p. xv). Perhaps, like language, material usage is situated both within a person and without, developing within each individual, while also being heavily influenced by cumulative knowledge passed down through culture. Indeed, C. Moon contends that a contemporary approach to materials in art therapy involves looking at material usage in terms of social construction. She describes the process of making meaning through art as a, "dynamic, ongoing, co-creative venture that involves the individual in dialectical interaction with social, cultural, and historical milieus." (p.56). She advises that each individual and the material they work with should be looked at within their specific context.

Huss (in C. Moon, 2010) furthers this view of materials in her examination of the use of embroidery in the Bedouin women of Israel. The author makes overall connections between the process and product of embroidery to Arabic culture. She writes that the 
involved process reflects a network of women working together, and that this network is expressed in the geometric patterns found within the embroidery. These patterns are symbolic of a cultural value of harmony and orderliness. In order to be able to make these connections, Huss had to take time to study the art practices of a culture that was not familiar to her. Additionally, she explored Bedouin history and other cultural practices, to understand the ways in which embroidery fit into the culture overall. Had she not done this, she might not have been able to see the potential metaphorical connections that the embroidery provided.

Different qualities of materials have been noted to bring out different kinds of metaphors. Somer and Somer (2000) go into detail about the qualities of glass as a material and the connections this might facilitate. For instance, as it is heated, glass can change its state from solid, brittle, and hard, to fluid and malleable. The authors offer that this could lead to clients identifying with this change in state, comparing increased fluidity with openness to making personal changes. Meanwhile, the act of breaking apart, and then creating a coherent whole out of broken parts, could relate to personal destruction and reformation. Finally, there are the qualities of reflection and transparence, which allow the client to either see themselves in the piece, to see through the piece, or to notice the light filtering through. Transparence in the glass, for instance, was noted to be interpreted as a feeling of personal transparency and exposure in a client. The client's feelings of transparency were addressed by having her paint onto glass, to obscure it.

To help hospice clients discover salient metaphors to work with, Whalen (2004) developed a directive that involves bringing a bag of differently textured items, and having the client close their eyes and pick the texture that most relates to them in the moment. As a 
case example notes, this provides an opportunity for personal identification with a physical object. Whalen, describing a session with a client, writes, "when she picked out something rumpled and metallic, she said, 'I am a crumpled piece of aluminum foil. I am folding myself like an accordion. I can't move around in bed. I get stuck."” (p.106). These personal descriptions lead to personal insight, and an increase of understanding between the client and therapist, as well as other caregivers.

Metaphor in art therapy: Product. The origins of art therapy in the United States are based around the exploration of client-made imagery as manifestations that have spontaneously emerged from the unconscious (Naumburg, 1987). Thus, the examination of metaphor in the art product has deep roots in the field. Figure 1 below is an example of client work pulled from a case study of Naumburg's, entitled, “The Dream of My Blue Evening Dress." Naumburg relates the process of having the client describe each element of the drawing. The drawing contains imagery of the client holding two heads - one of her mother (on the left) and one of Naumburg, her therapist. This is taken to be a clear sign of the client's growing fondness for her therapist, and her anger towards her mother. In other words, the spatial opposition of the two heads in the drawing is taken to be a sign of the opposition of those two people within the psyche of the client. 


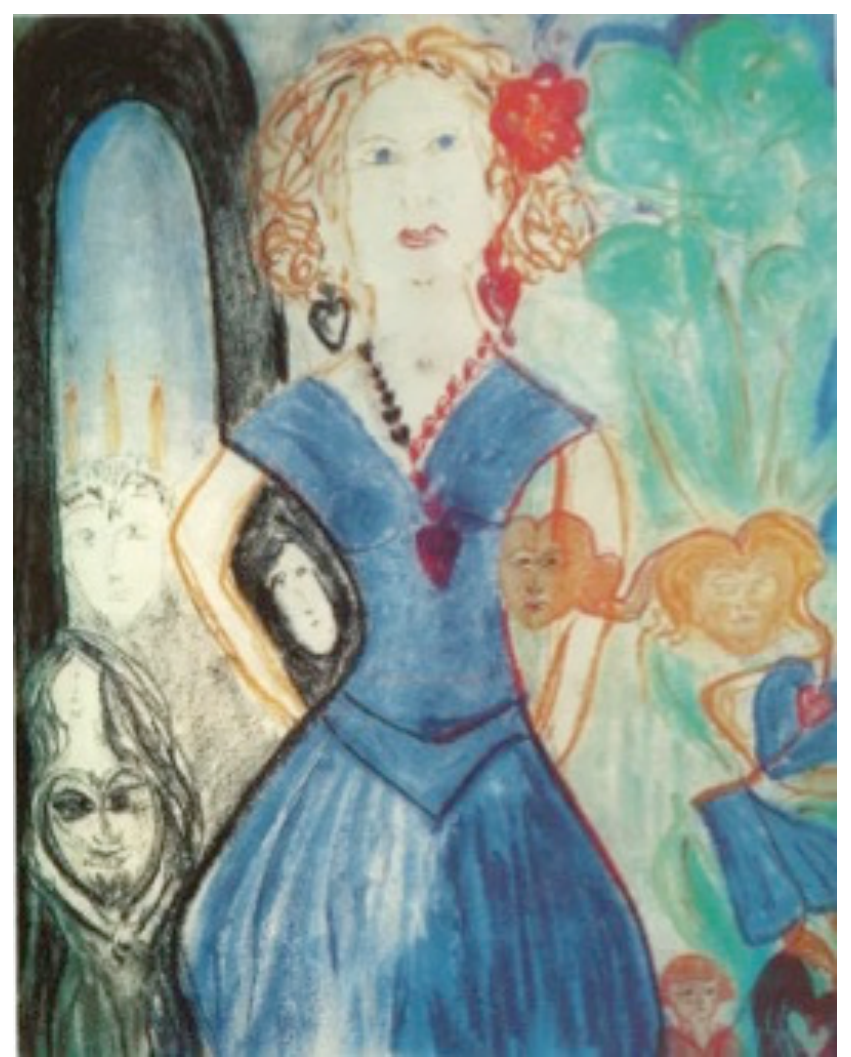

Figure 1. "The Dream of My Blue Evening Dress"

Wadeson (2010) notes, bluntly, “we think in images.” (p.9). In therapy, whether acknowledged or not, images are present in the mind of both the client and the therapist. Art therapy makes these images concrete. Once an artistic product exists, it is a separate entity from the artist who made it, something from the mind made real. This externalization provides a chance to literally look at what is going on inside the artist (Wadeson, 2010).

According to B. Moon (2007), the use of metaphor is one of the ways that clients and therapists can begin to understand these artistic products. B. Moon's book The Role of Metaphor in Art Therapy is the most prominent and explicit exploration of the use of metaphor in the field. In it, he coins the term "metaphoretician," which he defines as, "one who skillfully and spontaneously uses visual, aural, and kinetic metaphors to uncover and convey truths" (p.16). This, he writes, is his job as an art therapist. 
B. Moon defines metaphor with a literary perspective, citing its use in poetry as a way to increase understanding of complex emotions. He writes that art therapy goes "beyond" words, utilizing and highlighting clients' visual metaphors, many of which are too multifaceted to be summarized verbally. Inner worlds become concrete as they are created in physical form, both making room for observation and providing a distance from the issue. Moon's students and clients utilize trees, storms, pathways, and caves, among other imagery, as bases from which to explore emotions and relationships. Moon works with metaphors that clients bring to his studio, exploring them by adding sound or kinetic elements, expanding the metaphor through discussion or responsive art-making, and using the vocabulary of the given metaphor in interactions. Sometimes, it is this noticing, holding, and expanding of metaphors that helps the client to fully see and apply these metaphors to their lives in a meaningful way. Other times, Moon brings his own metaphors to the client to see if they resonate. For instance, in working with a group of adolescents at a treatment center, Moon made an educated guess that the group might resonate with the idea of their lives being "stormy" (p.75). In this instance, he was correct in his assumption, and the group took to imagining their storms, manifesting them in physical form.

As Moon illustrates, either the client or the therapist can bring metaphors to the session. Kidd and Wix (1996) describe a young client's use of heart imagery. The client, S, had been sexually abused and was seeing the authors for depression and poor school performance. During the course of group art therapy, $\mathrm{S}$ talked less and less, but drew hearts more and more. In the face of this lack of access to verbalization, the authors examine the evolution of her images, keeping in mind the potential significance of the heart on a wider, historical level, as well as on a personal 
level. They write, “...our challenge was to look to the image for clues in the visual qualities of the image-movement of line and color, placement and pattern, and spatial relationships-as echoed through descriptive metaphors," (p. 5), indicating that the authors understood S's visual imagery as being a metaphoric message of what was going on inside her. Figures 5-7, reproduced from the original article, demonstrate the progression of S's images, which show a progression in the types of line work used. The authors hypothesize that this line work indicates a message about progression from tangled messiness to touching and connection.

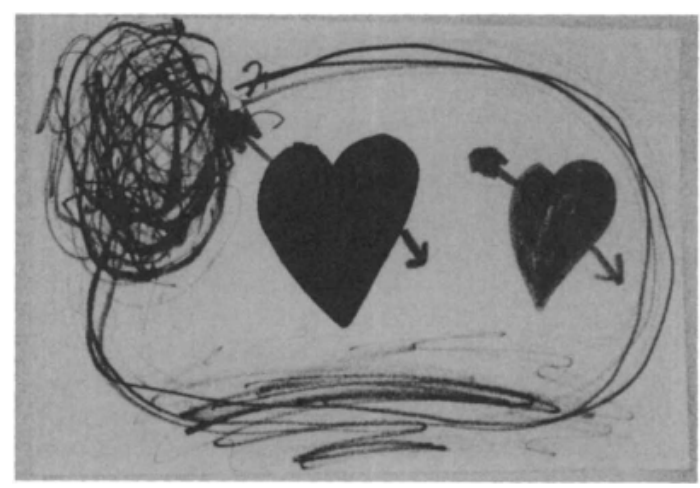

Figure 2. Separate tangled lines

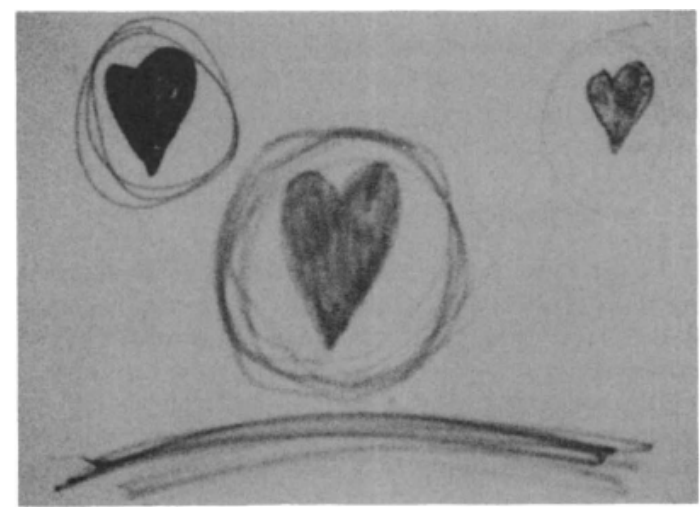

Figure 3. Lines encircling hearts 


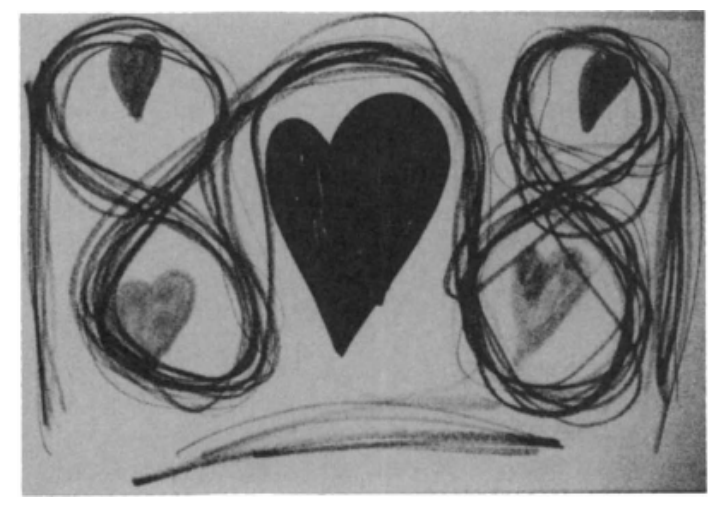

Figure 4. Encircled and connected hearts

Exemplifying metaphorical imagery provided by the therapist, Hanes (2008) describes his protocol used in the assessment of suicidality in jail inmates. Working with inmates on suicide watch, he brings them drawing supplies and invites them to "draw a road" (p.80). Hanes describes choosing this imagery for its accessibility and potential to provide distance from sensitive subjects that might not be so easily discussed in the jail setting. Though Hanes does not offer directions on how one might draw the road, he does offer examples of questions that could be asked to help a client begin to draw, such as (p.4):

Is this a straight road, curvy road, hilly road, flat road, etc.?

Is the road surface made of cement, dirt, brick, blacktop, etc.?

What is the condition of your road or roads?

Is there more than one road or more than one lane?

Are there any intersections? If so, is this a cross roads, T-intersection, or $Y$ intersection?

Where does the road begin? Where does the road end?

Are there any signs along your road? Do the signs have pictures and/or words? What is around your road, alongside, or in your road? 
These questions help the client to fully imagine their road and its surroundings. Though Hanes never explains the metaphorical implications of the task of drawing a road, the task seems to indicate to inmates that the road is metaphorical from the outset. Each case example described in the article proceeds to create a road that relates to his or her life, and verbally addresses those relationships. The participants are quoted as using phrases like "dead end," "highway to heaven," and "get on the right road," and depicting those ideas in their work. Unprompted, more than one participant viewed the road as functioning as a personal narrative, using the road as a kind of timeline of events. Figure 5 is an example of a client's drawing of a dead end, which was accompanied by her saying that "life has me going in circles, it's never the right way." (p.81). Clearly, the physical circularity of her drawing and her conception of her life are related. The accessing of the imagery of the road seems to have encouraged a metaphorical connection between her life trajectory and the literal idea of a road.

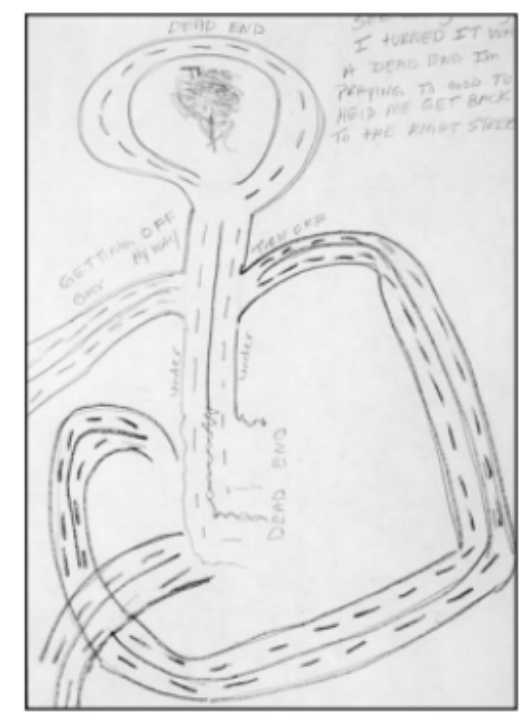

Figure 5. "Dead End" 
The choice of material could also be interpreted as a therapist's influence over the metaphors found in the final product. Chilton (2007) describes using altered books with clients. A book is considered by many to be a product in-and-of itself, thus the idea of altering books necessarily involves associations with books in general. Historically, a book contains knowledge. A client could be seen as covering over, or erasing, that knowledge. Simultaneously the readymade book format could encourage feelings of importance for the content that the client includes. The format lends itself to the creation of work that can be opened, pages turned, and closed, which changes the viewer's relationship with the product.

Combining client-provided and therapist-provided metaphors, the Draw A Story (DAS) assessment involves ready-made image prompts to jump-start clients into forming their own metaphorical pictures (Silver, 2007). Clients are invited to choose two images from a large group of options and create a new drawing to combine the images they have chosen. Afterwards, clients write a short narrative to describe what is going on in their image. These client-drawn images and stories are then rated on two scales: positive/negative emotion, and positive/negative self image. Repeated use of this assessment in multiple settings has shown that it is valid and reliable in uncovering depression in children and adolescents. This may be because children and adolescents with depression are more likely to utilize certain image prompts, and more likely to create drawings with conflict or sadness.

\section{Comics and Metaphor}

The DAS utilizes both image and text to gain understanding of the cognitive and emotional state of clients. Comics also harness the power of this combination of words and 
images, allowing them to communicate information in a manner distinct from static images or text alone. Examining communication in printed advertisements, Barthes (1977) notes that each advertisement image (without text) contains many different potential meanings, and is open to many different interpretations. The text included in the advertisement is what anchors and communicates meaning to the viewer. Barthes writes, "The caption...helps me to choose the correct level of perception, permits me to focus not simply my gaze but also my understanding." (p.156). Words and images simultaneously elaborate on and constrain meanings. Though comics do not necessarily have to include words, the combination of words and images holds a certain communicative power.

McCloud (1994), in his seminal work, Understanding Comics, defines comics as being "juxtaposed pictorial and other images in deliberate sequence, intended to convey information and/or to produce an aesthetic response in the viewer." (p.9). Notably, this definition does not mention the inclusion of words. However, the majority of comics do include verbal language, which often serves to further the storyline and enhance the understanding of the image for the reader. Additionally, comics often involve simplified (as opposed to realistic/photographic) imagery, which aids in understanding. The elimination of excess information from the image makes it easier to amplify the important details (McCloud, 1994). This combination of simplification of imagery, along with the constraining and explanatory presence of text, allows for a medium that is particularly suited to communicating information. Indeed, comics have been found to enhance understanding of course material for college biology students who were not majoring in science (Hosler \& Boomer, 2011). 
The format of comics itself may improve reading comprehension and memory of material. Reading retention was vastly increased among fourth graders who were given a text that included illustrations and were instructed to both pay attention to the illustrations and to form their own mental imagery of the content in their minds (Gambrell \& Jawitz, 1993). In this case, being actively engaged in looking at illustrations enhanced understanding of the text. Separately, language has been shown to aid in focusing perception, such that previously unrecognizable objects are made recognizable through verbal cues (Lupyan \& Ward, 2013). Taken together, these studies hint at the way that language and imagery interact with each other to enhance understanding of the world.

Conceptual metaphor theory has been applied to the study of visual images (Cohn, 2010; Forceville, 2015; Refaie, 2003). There is always some kind of translation occurring when an image is created (Refaie, 2003). A drawing of an object, no matter how realistic, is still a drawing and not the literal thing itself. Therefore, any image could be an instance of metaphor, in that it is being used to understand a concept that is not literally present. Drawings, as translations of reality into image, then also communicate something of how the artist sees and understands the world. Refaie (2003) acknowledges Barthes' (1977) theory of the image and text relationship described above, but then goes on to say that the image itself may portray something that is not fully describable with language. As well, a single panel political cartoon could communicate an idea much more quickly than language, using spatial arrangement, sizing, and other visual cues to display the relationships of people and ideas.

Comics, in their attempt to communicate narrative through the combination of sequential imagery and text, may be a uniquely brilliant way to examine the conceptual metaphor systems that make up thought, which is itself an interactive combination of 
imagery and language. For instance, emotions in comics are often portrayed using visual cues, like body posture, arm gestures, and small icons (i.e. droplets next to a face indicating anxiety) (Forceville, 2015). Forceville (2004) argues that comics may both highlight prevalent emotion-related conceptual metaphor systems as well as make visible metaphors that are less commonly verbalized in language.

Case example: Depression metaphors in comics. Refaie (2014) examined the depiction of depression in two graphic novels, Psychiatric Tales and Depresso. She notes that the comics format is an opportunity to make clear, and creatively expand upon, the metaphors that we use in everyday language. In Psychiatric Tales, the author juxtaposes imagery of a broken chain, window, and pencil with the words, "This is when I broke." (p.67) (Cunningham as cited in Refaie, 2014). These drawings make visually salient the conceptual metaphor system THE MIND IS A BRITTLE OBJECT as described in L\&J (1980). In this case, the author is using imagery of familiar physical objects breaking in order to convey the brittleness of his mind. In depicting their experience of depression, both authors rely on, and are influenced by, common metaphorical systems that relate depression to darkness, falling, and emptiness. Psychiatric Tales contains a panel that is completely black, signifying the "dark" mindset of the author. Meanwhile, Depresso features imagery of the protagonist falling down an elevator shaft, leading to his re-acquaintance with the symbol of his depression, a monster, who he thought he had lost contact with. Thus, the real, physical experience of falling down a dark hole is used to explain the feeling of falling back into a depression.

As Refaie (2014) notes, while both of these graphic novels utilize common metaphorical systems, they also manage to harness and display these metaphors in a creative 
way that allows for greater communication and understanding. While ways of talking about depression as darkness, descent, and emptiness may be relatively common, it is the portrayal of these words next to images of darkness, falling, and emptiness that highlight the metaphors present in everyday speech and make visceral the experience.

\section{Discussion}

CMT provides considerable support for the way that art therapists conceptualize the process and product of art-making. CMT posits that: 1) humans understand the world primarily by using the concrete to understand the abstract, 2) these metaphors are often based in bodily experience, and 3) these metaphors build on each other to allow for increasingly complex ways of understanding. In providing clients with materials and a space in which to explore their creativity, art therapists are providing what is, in essence, an experimental laboratory where concrete bases of metaphors can be discovered to aid in the understanding of abstract, intangible concepts. The following is a discussion of CMT as it applies to art therapy theory. Examples of the art-making process and product are utilized throughout to illustrate the synthesis of these two fields and to explore the implications for art therapy.

\section{Primary Metaphors}

Primary metaphors most directly relate to art therapy’s (AT) understanding of material quality and its effects on behavior during the process of art-making. As discussed above, primary metaphors are thought to be the most basic building blocks of thought. They pair common concrete experience with equally common yet less concrete bodily sensations and emotions. This idea gives support to the AT material continuum described by Rubin (1984) as freedom/order and laid out by B. Moon in tables 2 and 3 above (p. 26). For instance, an early association could be that fluidity is equal to a lack of mechanical control over an object. Imagine a young child putting their hand in a bucket of water and learning 
that they cannot grasp or predictably manipulate the water. This would lead to a connection between the concepts of FLUIDITY and overall LACK OF CONTROL. This primary metaphor could then be mapped onto an art material, such as wet clay, to create a connection, e.g. CLAY IS LACK OF CONTROL. In this case, the physical interaction with clay would become the source domain for the more abstract concept of lack of control, or perhaps an emotion that lack of control elicits, such as fear. However, as explained above, one source domain does not encompass all understanding of any particular target concept, and neither does one source domain have to be linked to one particular target concept. There would be competing metaphorical associations that arise over time, depending on the person and their context. Various life experiences would affect the potential metaphor systems associated with clay. For instance, one might learn to enjoy fluidity and lack of control through spending more time manipulating fluid materials, perhaps by learning to swim. Or, perhaps one grows up in a culture where clay is a ubiquitous art form. These examples could lead to metaphors such as CLAY IS PLEASURABLE or CLAY IS COMFORT, affecting the range of responses that a particular client would have to the material. The art therapist, by providing a supportive presence and creating a holding space for exploration, would also be responsible for the establishment of new, positive material associations. Potentially, continued feelings of security within the art space would lead to metaphors such as CLAY IS SECURITY. Continued interaction with a fluid material in this supportive environment could lead to feelings of mastery, creating the somewhat paradoxical new metaphor CLAY IS CONTROL. At the same time, the original primary metaphor, CLAY IS LACK OF CONTROL, would still likely have a strong hold and could re-emerge depending on the circumstance. ${ }^{2}$

\footnotetext{
2 Please see Supplementary Materials for further exploration of the interaction of primary metaphor, embodiment, art materials, and human development.
} 


\section{Experiential Basis of Metaphor and Embodiment}

The body is necessarily involved in AT, whether clients are manipulating materials, their own body, or accessing previous sensations and perceptions through memory. CMT work surrounding embodiment shows that there is a vast amount of information coming from sensation and perception that is available to create metaphorical connections and systems of metaphor. This work provides incredible support for the theory that our bodies are the basis from which we make sense of ourselves and our environment. Essentially, our experience in our bodies is what gives us the grounding to be able to comprehend abstract concepts. Incorporating the work done in CMT both provides additional avenues to explore in art therapy and also provides support for the work currently being done.

In terms of new avenues to explore, CMT metaphor systems that have been established could be applied within the therapeutic space, be it the art studio, community area, or hospital room. For instance, the metaphor HAPPY IS UP, could lead to work being hung from the ceiling to encourage an upward focus. Therapists could also be on the lookout for client language that reflects systems of metaphor, such as the phrase "my spirits rose," and consider highlighting this for the client and offering it as inspiration for art-making.

AT already makes use of many metaphors mentioned above in the CMT embodiment section. The exploration of glass as a material by Somer and Somer (2000) in part corresponds to the metaphor system THE MIND IS A BRITTLE OBJECT. In this case, glass was the brittle material that corresponded to the mind, or the self. The authors noted that experience of this material becoming more fluid as it was heated resulted in expanded notions of what the self was capable of. CMT supports the idea that this physical material would potentially lead to insights about more complex and intangible concepts. 
Chilton (2007) mentions that one of the benefits of using altered books is as a container for emotional material. This corresponds to the general system of ontological metaphors, which include giving containment and shape to concepts that have no physical form. Ideas, emotions, and the mind, are just some of the concepts that have been conceived as containers in English (Gibbs, 1996). Seeing the body as a container for emotions is a metaphor that spans different cultures (Kovecses in Radman, 1995). Thus, CMT adds considerable support to the idea that a physical container could be a therapeutic tool to help contain something as abstract as an emotion.

Sweetser's (1998) work on gestural metaphor suggests that even small hand movements can be used to facilitate communication. These gestures can enhance understanding for both the viewer and the person speaking/gesturing. This provides support for the idea that the process of art-making, which generally involves hand or body movements, is itself a method of communication for the artist/client. At the same time, it dovetails with the gestural movements developed by Florence Cane (1983) that were thought to be beneficial to the creative process. Overall, the idea that gesture affects cognition, and is used as a movement-based metaphor to understand abstract concepts, hints at the possibility that the body must be involved in any kind of therapeutic work.

Finally, an essential theory in AT, mentioned above in B. Moon (2007), is the idea that the creation of artwork enables the artists to obtain emotional distance from whatever is going on in their head. Equating literal distance from the self to emotional distance is a kind of metaphor that would be supported by the idea of embodied cognition.

\section{How Metaphors Are Created}

Metaphors necessarily highlight some aspects of a concept and hide others. Thus, the source domain used for a target concept matters. If art therapists consider materials and 
artwork to be the concrete source domain for more abstract target concepts, the qualities of the material being used are incredibly important to the therapeutic process. Though clients could have a wide range of potential associations with any one material, there are certain properties that will be constant. For instance, wet clay will never be brittle or hard. Though clay may not necessarily invite regression, it is much more likely to do so than other, more solid materials. This same idea applies to all other materials, each of which have certain basic properties that will constrain the availability of metaphorical connections. If the metaphor is to be found in the imagery of the final product, the quality of the material will still have influence. For instance, a dancing couple as depicted in watercolor will have a more fluid quality than a dancing couple depicted in pencil.

\section{Evolution of Metaphor}

Through visual and verbal communication, art therapists have the ability to highlight conventional metaphor systems and encourage the creation of novel metaphors. Because art therapists are paying such close attention to the person and to their surroundings, they are capable of highlighting connections that are particularly salient to a client. Though ultimately it would be up to the client to find meaning in their metaphors, art therapists can promote and validate the value of existing systems and novel systems. Art therapists can also be guides to the creative manipulation and evolution of metaphor systems that were once thought to be rigid. For instance, in marital counseling, were an art therapist to note that a particular couple had an overarching metaphor system of LOVE IS A JOURNEY, and that this journey was at a dead end, they could potentially suggest a new metaphor of LOVE IS A COLLABORATIVE WORK OF ART. This metaphor would be especially salient if the couple had the real life experience of creating a collaborative work of art.

\section{Metaphor and the Unconscious}


Keeping in mind that much of conventional metaphor is implicit, it would be unusual for the average person to be able to notice the metaphorical systems that surround them without considerable practice. It would take another person, who is attuned to the potential of metaphor, to be able to notice and attend to the metaphor systems a person, or culture, has developed over time. Art therapists would be uniquely suited to this task, as they would be able to notice multiple types of metaphoric expression, whether verbally, visually, or behaviorally.

\section{Emotion and Metaphor}

Learning how to understand and live with changing emotions is one of the greatest tasks that people undertake. More often than not, dealing with complex emotions is an important part of therapeutic work, not to mention day-to-day life. Emotion metaphors that have been established by CMT provide a wellspring of potential inspiration for work in AT. Systems mentioned above include ANGER IS HEAT and ANGER IS A FLUID. Knowing this, an art therapist could either use a metaphorical statement such as "boil with anger" as the inspiration for a directive, or allow those systems to aid in the choice of materials and imagery they offer.

The master metaphor EMOTIONS ARE FORCES mentioned above provides support for B. Moon's (2007) use of the metaphor of a storm when working with adolescents in a treatment center. The use of storm imagery, and weather in general, is almost guaranteed to provoke connections with emotion, as the weather is an uncontrollable, unpredictable phenomenon that each of us have intimate history with. Depending on the kind of storm or weather being talked about, this kind of imagery could provide metaphorical connections cross-culturally.

\section{Cultural Variation in Metaphor}


Metaphor is essential to cognition, but this is not to say that the same metaphorical connections are present in every culture, or every person. While evidence suggests that there are areas of considerable overlap, there are also areas of considerable difference. As art therapists know well, it is important to tailor our work to the specific group or person we are working with, and be mindful of varying backgrounds. There are instances of CMT being studied in relation to other languages. For instance, Moradi and Mashak (2013) compared the conceptualization of sadness in Persian and English, finding many similarities, but also various cultural differences, such as the mapping, "EYES ARE A NEST FOR SADNESS." Knowing that this mapping exists in Persian could potentially help to inform or guide an art therapist when working with a client who speaks Persian as a first language.

As noted above (p. 29-30), embroidery is a salient metaphorical base for the Bedouin women of Israel (Huss, in C. Moon, 2010). Embroidery would likely have different connotations depending on its context. In another culture, different aspects of the embroidery process and product might be mapped onto target concepts. Elsewhere, embroidery might be so foreign that it would not be a relevant source concept at all.

\section{Transfer of Knowledge}

Analogical reasoning is an extension of metaphorical understanding, and analogies are often used by scientists to understand complex ideas. However, connections between two congruous concepts do not necessarily happen spontaneously. Rather, people can be subject to functional fixedness (Duncker, 1945). Gick and Holyoak (1980) found that students were unlikely to make connections between a helpful analogy and a science problem unless they were given encouragement to do so. Though AT does provide a strong basis from which metaphorical connections can be made, it's possible that clients will have trouble making these kinds of connections without encouragement to notice them. 


\section{Areas for Further Study}

This manuscript is only the beginning of the exploration that could be done to align conceptual metaphor theory and art therapy. These fields have the potential to enhance each other. There is work being done to study the neural basis for CMT (Lakoff, 2014) which would provide further grounding for art therapy. At the same time, the AT material continuum has the potential to provide the basis for research that would both strengthen AT claims while also providing evidence for the pervasiveness of conceptual metaphors. Some questions to consider could be: does brittle glass consistently invite comparisons to a brittle self? Does utilizing a container as part of an art therapy directive result in similar metaphorical connections cross-culturally? Does the way that someone handles collage materials consistently align with their personality?

\section{Conclusion}

Though metaphor is often thought to be a tool that is only wielded by professional artists, the truth is that everyone is using metaphors every day to understand themselves and the world. Artists stand out as those who consistently train themselves to be able to see the potential for metaphor in objects. We contend that art therapists, as both scholars of the arts and of psychology, have been trained to see metaphor on a level that surpasses artists and therapists alone. This is due to their training in: 1) the properties of physical materials and their affect on artistic process and product, 2) viewing the process and product of artwork as being metaphorical for the artist, and 3) attending to the socio-cultural context of clients. Art therapists provide clients with a wide range of concrete materials that offer themselves as source domains for intangible target concepts. Thus, CMT adds considerable weight to the idea that the task of the art therapist is to become a metaphoretician. The more that art therapists can see the polysemy of materials, product, and behavior, the more art therapists 
can understand and communicate with their clients. Further, art therapists can encourage this understanding of polysemy with their clients, enabling them to consciously create systems of connection and meaning with their surrounding environment.

Art therapists continue to contribute to a growing body of research studying the therapeutic benefits of art therapy. At the same time, some practitioners choose to describe what they do as a kind of magic. This combination of perspectives continues to shape and inform the field. McNiff (1992) writes that he considers his work to be that of a shaman. We do not disagree with this, but rather contend that intimate knowledge of the ways that concrete materials and images affect understanding of abstract concepts will only serve to enhance the feeling of wonder at what occurs in art therapy. A deep understanding of metaphor and its essential place in cognition will not take away from the thrill felt when artwork successfully facilitates a connection for a client, therapist, or community. Instead, conceptual metaphor theory has the potential to strengthen the foundations of art therapy, increase recognition of the value of the field, and encourage further collaboration with other disciplines. 


\section{References}

Ackerman, J. M., Nocera, C. C., \& Bargh, J. A. (2010). Incidental Haptic Sensations Influence Social Judgments and Decisions. Science, 328(5986), 1712-1715. http://doi.org/10.1126/science.1189993

Allen, P. (1995). Art Is a Way of Knowing. Boston: Shambhala.

Association of Psychological Science. [PsychologicalScience]. (2015, April 7). George Lakoff: How brains think: The embodiment hypothesis [Video file]. Retrieved from: https://www.youtube.com/watch? $\mathrm{v}=$ WuUnMCq-ARQ

Barthes, R. (1977). "The Rhetoric of the Image." In his book Image-Music-Text, trans. S. Heath. 1964; rpt. London: Wm. Collins Sons and Co., pp. 32-51.

Bowdle, B. F., \& Gentner, D. (2005). The Career of Metaphor. Psychological Review, 112(1), 193-216. http://doi.org/10.1037/0033-295X.112.1.193

Cane, F. (1983). The Artist in Each of Us (Revised edition). Craftsbury Common, Vt: Art Therapy Publications.

Chilton, G. (2007). Altered books in art therapy with adolescents. Art Therapy: Journal of the American Art Therapy Association, 24(2), 59-63.

Cohn, N. (2010). Extra! Extra! Semantics in comics!: The conceptual structure of Chicago Tribune advertisements. Journal of Pragmatics, 42, 3138-3146.

Duncker, K. (1945). On problem solving. Psychological Monographs, 58(5).

Forceville, C. (2005). Visual representations of the idealized cognitive model of anger in the Asterix album La Zizanie. Journal of Pragmatics, 37(1), 69-88. http://doi.org/10.1016/j.pragma.2003.10.002

Forceville, C. (2015). Theories of conceptual metaphor, blending, and other cognitivist perspectives on comics. In N. Cohn (Ed.), The Visual Narrative Reader. London: Bloomsbury.

Gambrell, L., \& Jawitz, P. B. (n.d.). Mental imagery, text illustrations, and children's story comprehension and recall. Reading Research Quarterly, 28(3), 265-273.

Gentner, D. (1983). Structure-Mapping: A Theoretical Framework for Analogy. Cognitive Science, 7, 155-170.

Gibbs, R. W. (1996). Why many concepts are metaphorical. Cognition, 61(3), 309-319.

Gibbs, R. W. (2011). Evaluating Conceptual Metaphor Theory. Discourse Processes, 48(8), 529-562. http://doi.org/10.1080/0163853X.2011.606103

Gibbs, R. W., Gould, J. J., \& Andric, M. (2006). Imagining Metaphorical Actions: Embodied Simulations Make the Impossible Plausible. Imagination, Cognition and Personality, 25(3), 221-238. http://doi.org/10.2190/97MK-44MV-1UUF-T5CR

Gick, M., \& Holyoak, K. (1980). Analogical problem solving. Cognitive Psychology, 12, 306-355.

Grady, J. (1997). Foundations of Meaning: Primary Metaphors and Primary Stress. eScholarship.

Grady, J. (2007). Metaphor. In D. Geeraerts \& H. Cuyckens (Eds.), The Oxford Handbook of Cognitive Linguistics (pp. 187-213). Oxford: Oxford University Press.

Hanes, M. (2008). Signs of suicide: Using road drawings with inmates on suicide observation at a county jail. Art Therapy: Journal of the American Art Therapy Association, 25(2), 78-84.

Hosler, J., \& Boomer, K. B. (2011). Are Comic Books an Effective Way to Engage Nonmajors in Learning and Appreciating Science? CBE Life Sciences Education, 10(3), 309-317. http://doi.org/10.1187/cbe.1007-0090

Kidd, J., \& Wix, L. (1996). Images of the heart: Archetypal imagery in therapeutic artwork. Art Therapy: Journal of the American Art Therapy Association, 13(2), 108-113.

Kovecses, Z. (1995). The "Container" Metaphor of Anger in English, Chinese, Japanese, and Hungarian. In Z. Radman (Ed.), From a Metaphorical Point of View: A Multidisciplinary Approach to the Cognitive Content of Metaphor. Walter de Gruyter GmbH \& Co KG.

Kovecses, Z. (2008). Metaphor and emotion. In R. W. Gibbs (Ed.), The Cambridge Handbook of Metaphor and Thought (pp. 380-396). Cambridge University Press. Retrieved from http://dx.doi.org/10.1017/CBO9780511816802

Kovecses, Z. (2010). Metaphor: A Practical Introduction, 2nd Edition (2e edition). New York: Oxford University Press.

Kramer, E. (2000). Art as Therapy: Collected Papers. (L. A. Gerity, Ed.). Jessica Kingsley Publishers.

Lakoff, G. (1992). Metaphor: The language of the unconscious. The theory of conceptual metaphor applied to dream analysis. Paper presented at The Association for the Study of Dreams, University of California at Santa Cruz, CA.

Lakoff, G. (2014). Mapping the brain's metaphor circuitry: metaphorical thought in everyday reason. Frontiers 
in Human Neuroscience, 8.

Lakoff, G., \& Johnson, M. (1980). Metaphors We Live By. Chicago: University Of Chicago Press.

Landgarten, H. B. (1993). Magazine Photo Collage: A Multicultural Assessment and Treatment Technique. Brunner/Mazel Publishers.

Lupyan, G., \& Ward, E. J. (2013). Language can boost otherwise unseen objects into visual awareness. Proceedings of the National Academy of Sciences, 110(35). http://doi.org/10.1073/pnas.1303312110

Martin, R. (1997). Looking and reflecting: returning the gaze, re-enacting memories and imagining the future through phototherapy. In S. Hogan (Ed.), Feminist Approaches to Art Therapy (pp. 150-175). London: Routledge.

McCloud, S. (1994). Understanding Comics: The Invisible Art (Reprint edition). New York: William Morrow Paperbacks.

McNiff, S. (1992). Art as Medicine: Creating a Therapy of the Imagination. Boston: Shambhala.

Miles, L. K., Nind, L. K., \& Macrae, C. N. (2010). Moving Through Time. Psychological Science, 21(2), 222223. http://doi.org/10.1177/0956797609359333

Moon, B. (1992). Essentials of Art Therapy Education and Practice. Springfield, IL: Charles C Thomas Pub Ltd.

Moon, B. (2007). The Role of Metaphor in Art Therapy: Theory, Method, and Experience. Springfield, IL: Charles C Thomas Pub Ltd.

Moon, C. (2002). Studio Art Therapy. London, England: Jessica Kingsley Publishers.

Moon, C. (2010). Materials and Media in Art Therapy: Critical Understandings of Diverse Artistic Vocabularies. New York: Routledge.

Moradi, M., \& Mashak, S. (n.d.). A comparative and contrastive study of sadness conceptualization in persian and english. English Linguistics Research, 2(1).

Naumburg, M. (1987). Dynamically Oriented Art Therapy: Its Principles and Practice. Chicago, IL: Magnolia Street Publishers.

Nummenmaa, L., Glerean, E., Hari, R., \& Hietanen, J. K. (2014). Bodily maps of emotions. Proceedings of the National Academy of Sciences, 111(2), 646-651. http://doi.org/10.1073/pnas.1321664111

PsychologicalScience. (n.d.). George Lakoff: How Brains Think: The Embodiment Hypothesis. Retrieved from https://www.youtube.com/watch?v=WuUnMCq-ARQ

Refaie, E. E. (2003). Understanding visual metaphor: the example of newspaper cartoons. Visual Communication, 2(1), 75-95. http://doi.org/10.1177/1470357203002001755

Refaie, E. E. (2014). Looking on the Dark and Bright Side: Creative Metaphors of Depression in Two Graphic Memoirs. A/b: Auto/Biography Studies, 29(1), 149-174. http://doi.org/10.1080/08989575.2014.921989

Rubin, J. A. (1984). Child Art Therapy: Understanding and Helping Children Grow Through Art (Second Edition). New York: Van Nostrand Reinhold.

Schacter, D. L. (1987). Implicit Memory: History and Current Status. Journal of Experimental Psychology: Learning, Memory, and Cognition, 13(3), 501-518.

Seiden, D. (2001). Mind Over Matter: The Uses of Materials in Art, Education, and Therapy. Chicago, IL: Magnolia Street Publishers.

Sholt, M., \& Gavron, T. (2006). Therepeutic Qualities of Clay-work in Art Therapy and Psychotherapy: A Review. Art Therapy: Journal of the American Art Therapy Association, 23(2), 66-72.

Silver, R. (n.d.). The Silver Drawing Test and Draw a Story. London: Routledge.

Somer, L., \& Somer, E. (2000). Perspectives on the Use of Glass in Therapy. American Journal of Art Therapy, $38,75-80$.

Springsteen, B. (1984). I'm on fire [Vinyl]. New York: Columbia.

Sweetser, E. (1998). Regular metaphoricity in gesture: Bodily-based models of speech interaction. In Actes du $16 e$ Congrès International did Linguists (CD ROM). Oxford: Elsevier.

Sweetser, E. (2006). Looking at space to study mental spaces: Co-speech gesture as a crucial data source in cognitive linguistics. In M. Gonzalez-Marquez, I. Mittelberg, S. Coulson, \& M. J. Spivey (Eds.), Human Cognitive Processing (Vol. 18, pp. 201-224). Amsterdam: John Benjamins Publishing Company. Retrieved from https://benjamins.com/catalog/hcp.18.15swe

Thibodeau, P. H., \& Boroditsky, L. (2011). Metaphors We Think With: The Role of Metaphor in Reasoning. PLOS ONE, 6(2), e16782. http://doi.org/10.1371/journal.pone.0016782

Tseng, M., Hu, Y., Han, W.-W., \& Bergen, B. (2014). "Searching for Happiness" or "Full of Joy"? Source Domain Activation Matters. Annual Meeting of the Berkeley Linguistics Society, 31(1). http://doi.org/10.3765/bls.v31i1.894 
Wadeson, H. (2010). Art Psychotherapy (Second). Hoboken, New Jersey: John Wiley \& Sons.

Whalen, D. (2004). Meeting your metaphor: The use of the arts and the imagination with dying persons. In R. Magniant (Ed.), Art Therapy with Older Adults. Springfield, IL: Charles C Thomas Pub Ltd.

Williams, L. E., \& Bargh, J. A. (2008). Experiencing Physical Warmth Promotes Interpersonal Warmth. Science (New York, N.Y.), 322(5901), 606-607. http://doi.org/10.1126/science.1162548

Zhong, C.-B., \& Liljenquist, K. (2006). Washing away your sins: threatened morality and physical cleansing. Science (New York, N.Y.), 313(5792), 1451-1452. http://doi.org/10.1126/science.1130726

\section{Appendix}

See next page for appendix materials. 


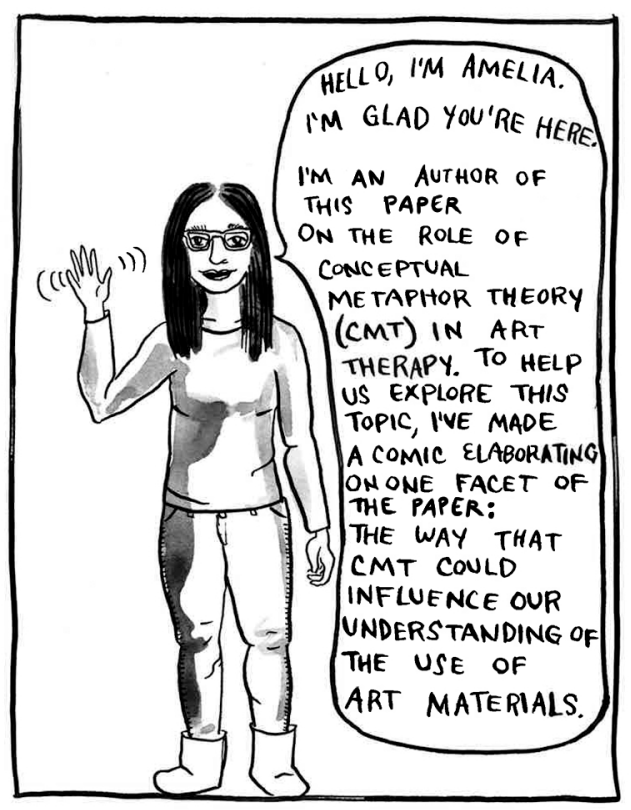

AS YOU CONTINUE, KEEP IN MIND THAT CONCEPTUAL METAPHORS :

1) WORK FROM THE CONCRETE TO THE ABSTRACT

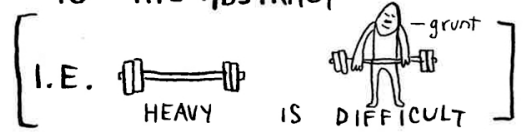

2) ARE BASED IN BODILY EXPERIENCE

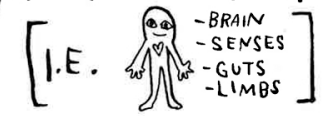

3) BUILD ON EACH OTHER OVER TIME, FORMING INTERCONNECTED CONCEPTUAL SYSTEMS.

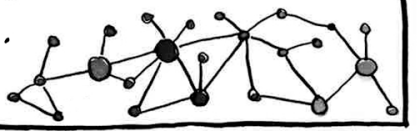

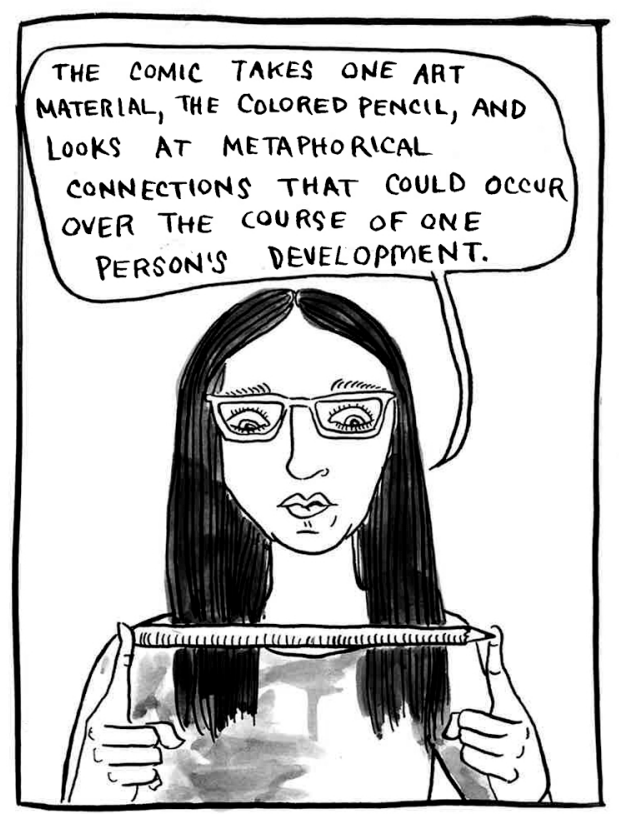

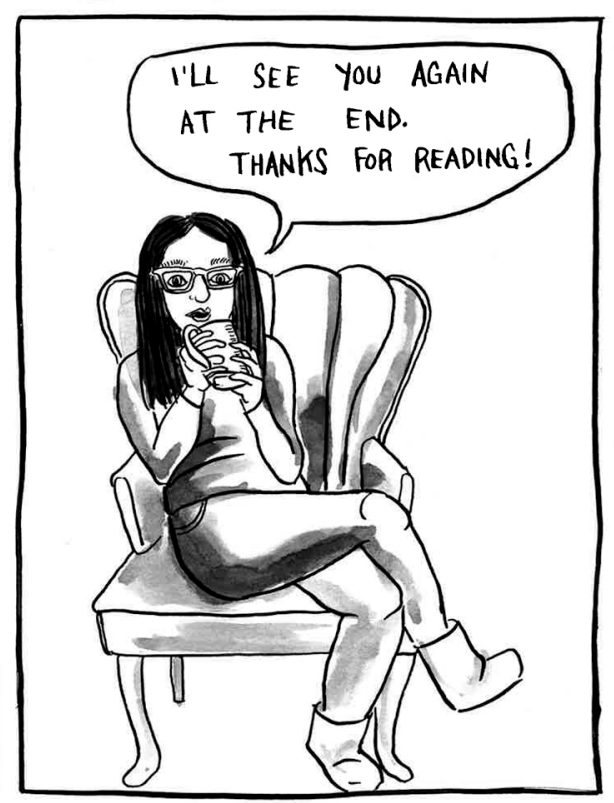


IMAGINE YOU ARE A BABY.

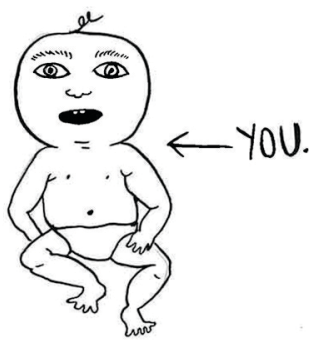

LET'S LOOK THROUGH

YOUR EYES

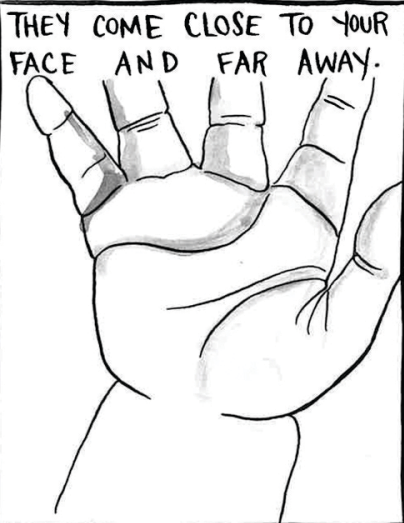

IT IS HARD AND STURDY AND DOES NOT CHANGE ITS SHAPE.

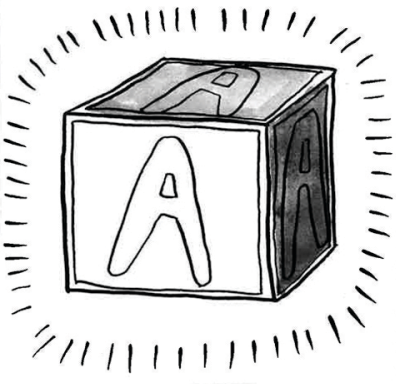

HERE ARE YOUR HANDS. AREN'T THEY AMAZING?

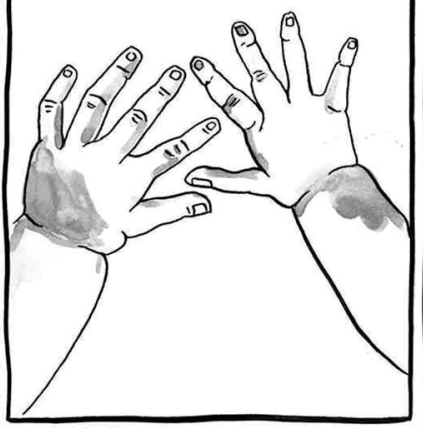

THEY CAN EVEN TOUCH AND MOVE THINGS.

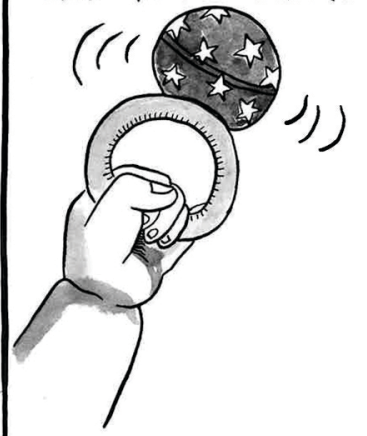

HERE ARE SOME MASHED POTATOES.

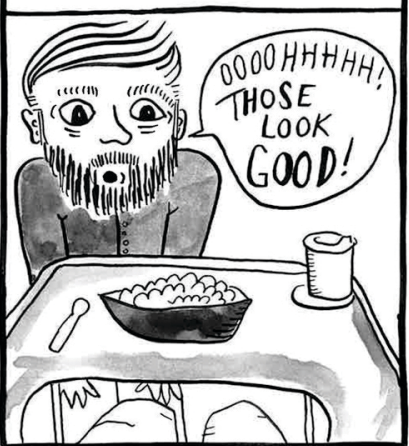

THEY OPEN AND CLOSE.
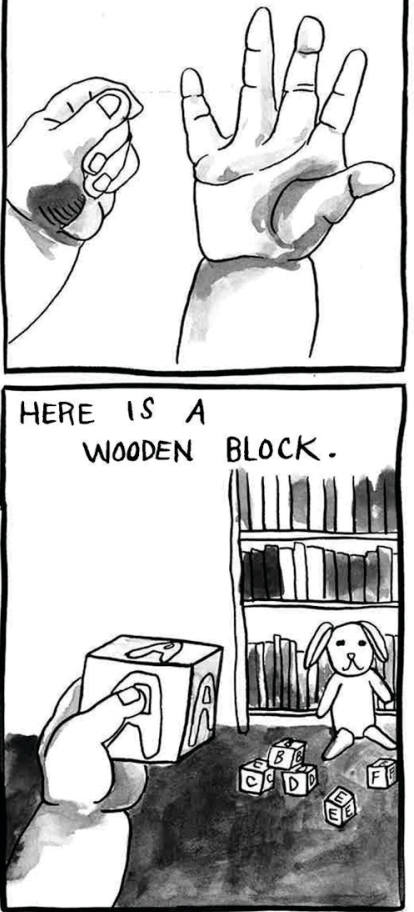

THEY ARE SQUISHY AND DO NOT HOLD THEIR SHAPE.

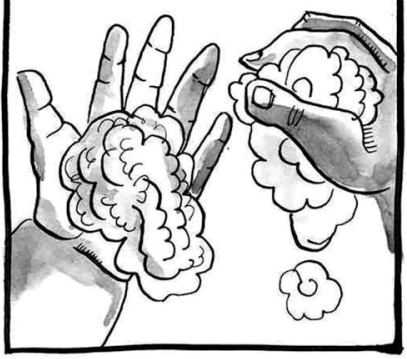




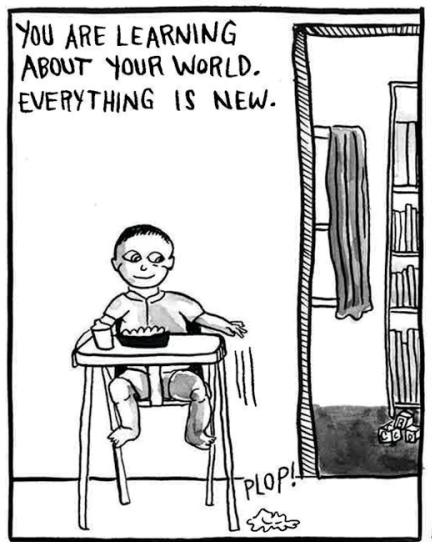

LATER...

YOU ARE FIVE YEARS OLD.

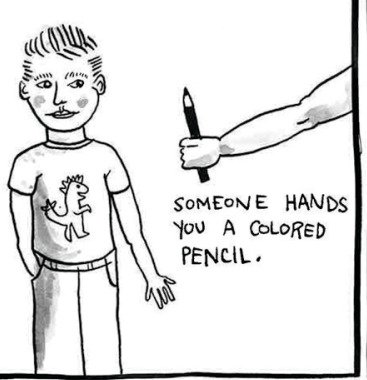

YOU LEARN IT TAKES A LOT TO FILL UP A PAGE WITH THOSE MARKS.

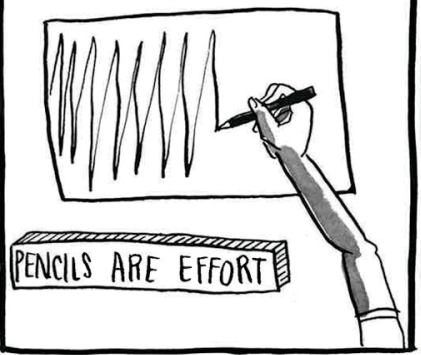

YOU FIND THAT THE HARD THING IS CONSISTENT, THE SOFT THING IS CHANGEABLE.

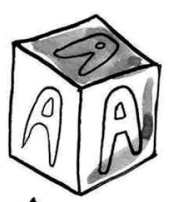

MALLEABLE, RESPONSIVE
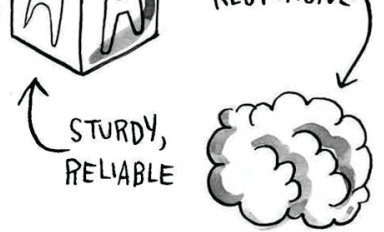

IT IS HARD, LIKE THE
BLOCKS YOU USED TO PLAY WITH.

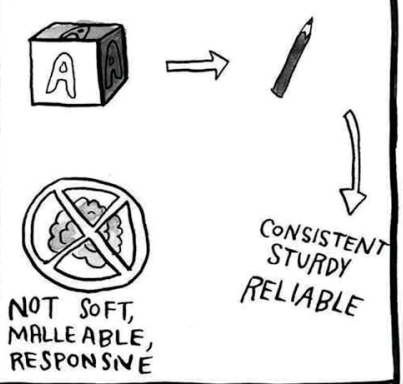

YOU IEARN TO HOLO THE PENCIL SO IT FEELS GOOD IN YOUR HAND, LIKE AN EXTENSION OF IT.

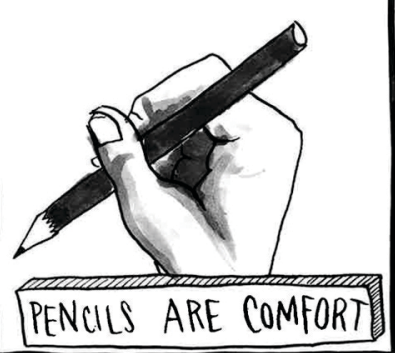

TO MAKE SENSE OF EVERYTHING, SYSTEMS + CATEGORIES ARE BEING FORMED WITHOUT YOU REALIZING IT.

HARD IS CONSISTENT E33 SOFT IS MALLEABLE FROM HERE, YOU WILL BUILD ON THIS KNOWLEDGE TO CREATE FURTHER METAPHORICAL ASSOCIATIONS.

YOU LEARN IT MAKES A CERTAIN KIND OF MARK ALWAYS THE SAME WIDTH.

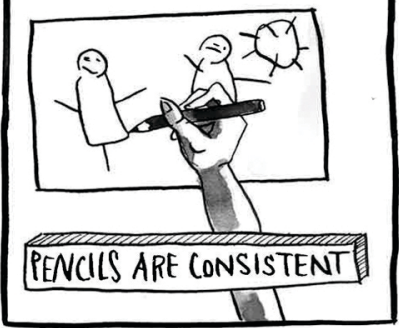

THIS HARD, CONSISTENT OB)ECT BECOMES ATTACHED TO IMPORTANT BUT LESS TANGIBLE FEELINGS AND EXPERIENCES. 


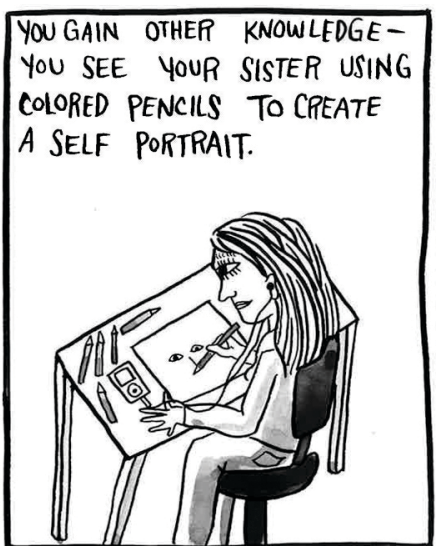

YOU BEGIN TO THINK THAT PENCILS ARE RELATED TO BEING GROWN UP.

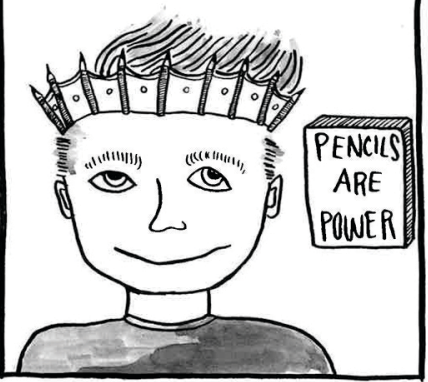

YOU GROW OLDER. THROUGHOUT YOUR LIFE, YOU SEE COLORED PENCILS, AND SIMILAR MATERIALS, USED PERIODICALLY.

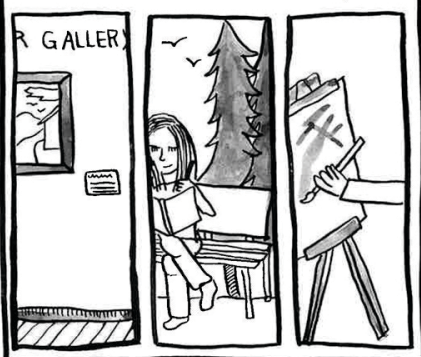

SHE USED THEM WITH CONCENTRATION AND CARE.
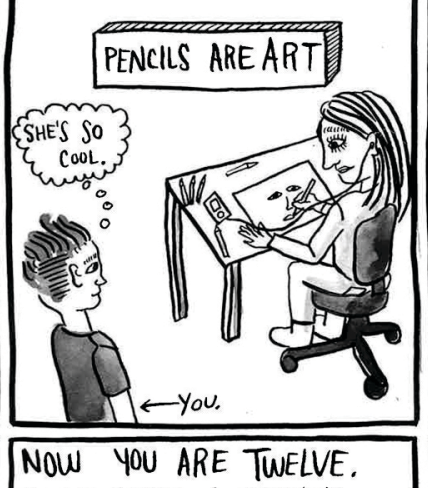
YOU'VE MADE A DRAWING WITH COLORED PENCILS AND YOU SHOW IT TO YOUR MOTHER, HOPING FOR APPRONAL.

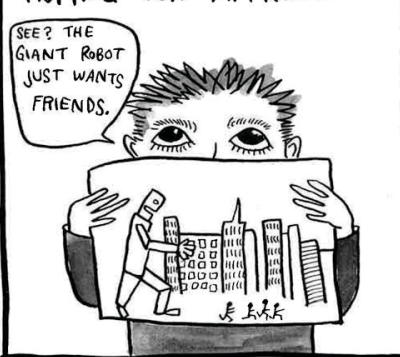

THEY DON'T FEEL LIKE YOUR TOOLS. YOU ARE NOT AN ARTIST.

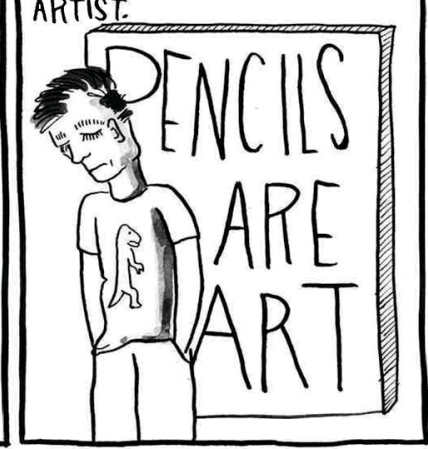

YOU ALSO SEE ADULTS USE SIMILAR LOOKING THINGS TO SIGN DOCUMENTS AND DO ADULT THINGS.
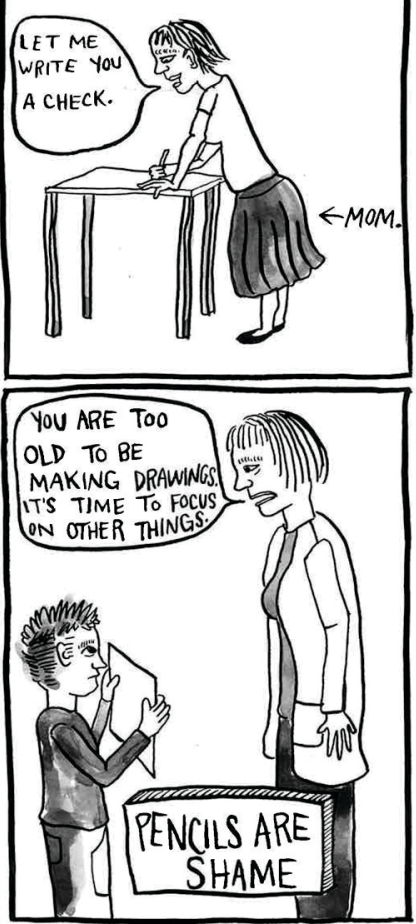

TIME GoES BY. YOU HAVE A WIFE AND A DAUGHTER.

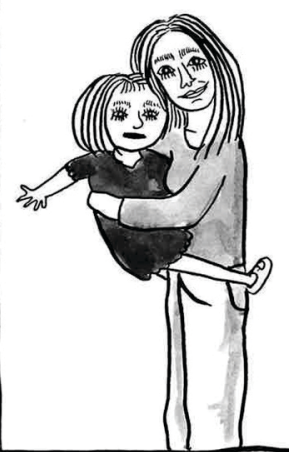




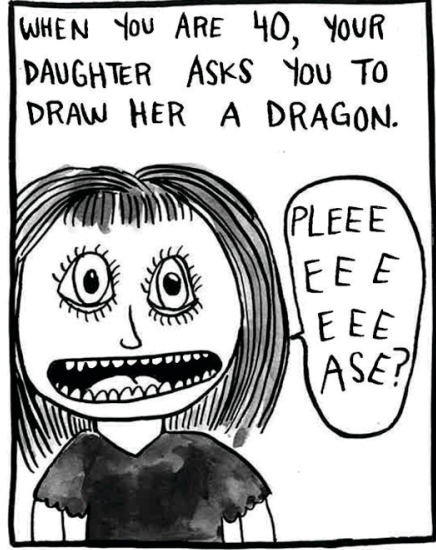

BUT THEN YOU FEEL THE

PENCIL IN YOUR HAND.

YOU FEEL THE HARDNESS.

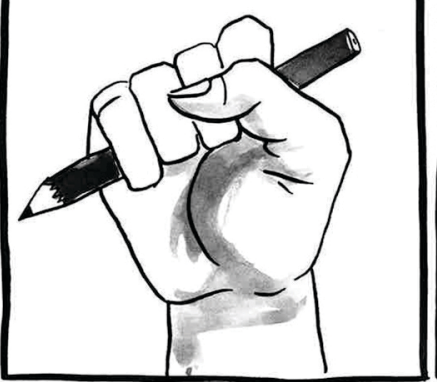

AS YOU DRAW, SOME PART OF YOU ALSO FEELS THE

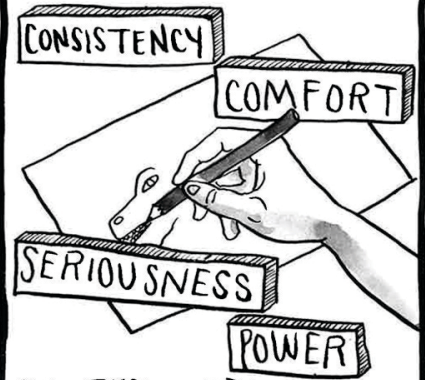

ALL THOSE METAPHORS FROM LONG AGO.

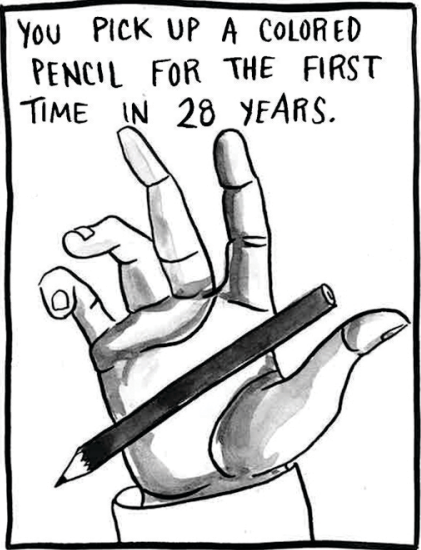

YOU SEE THE SHAPE OF IT.

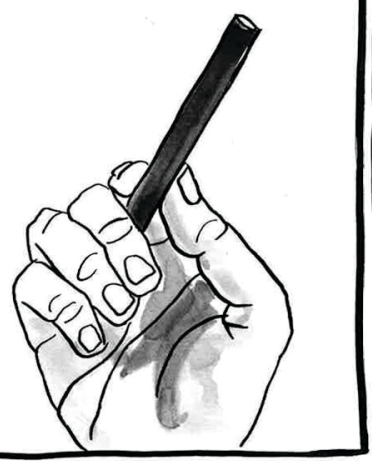

AS YOU DRAW BY YOUR DAUGHTER, YOU NOTICE HER ENGAGEMENT.

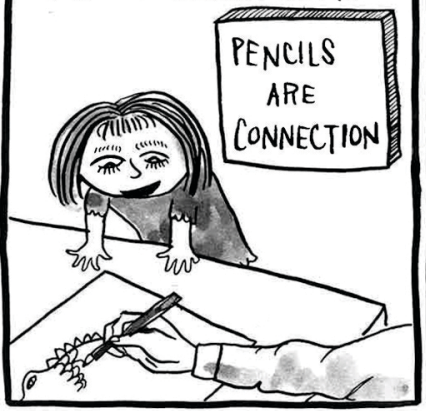

YOU FEEL SCARED, LIKE YOU CAN'T DO THIS, LIKE YOU ARE DOING SOMETHING BAD.

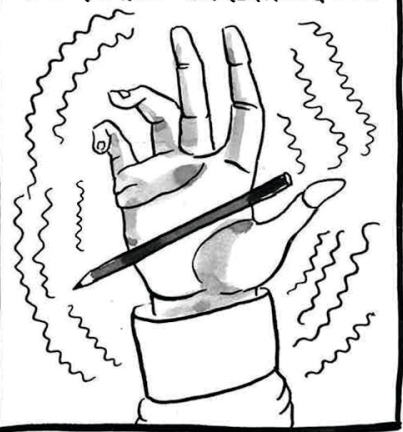

YOU CAN EVEN SMELL IT A LITTLE BIT.

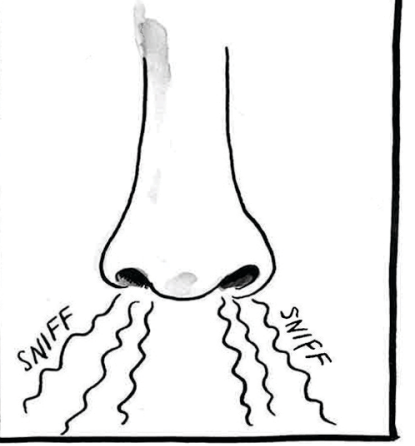

BECAUSE THE PENCIL AFFORDS YOU THE ABILITY TO MAKE SMALL DETAILS, WHEN YOUR DAUGHTER ASKS FOR SCALES, YOU CAN DO THIS FOR HER.

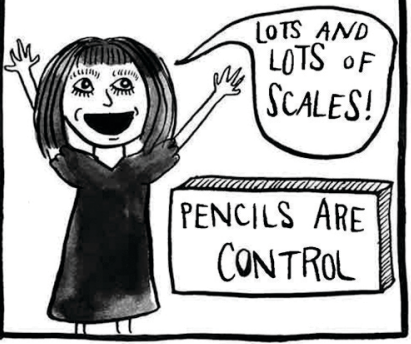



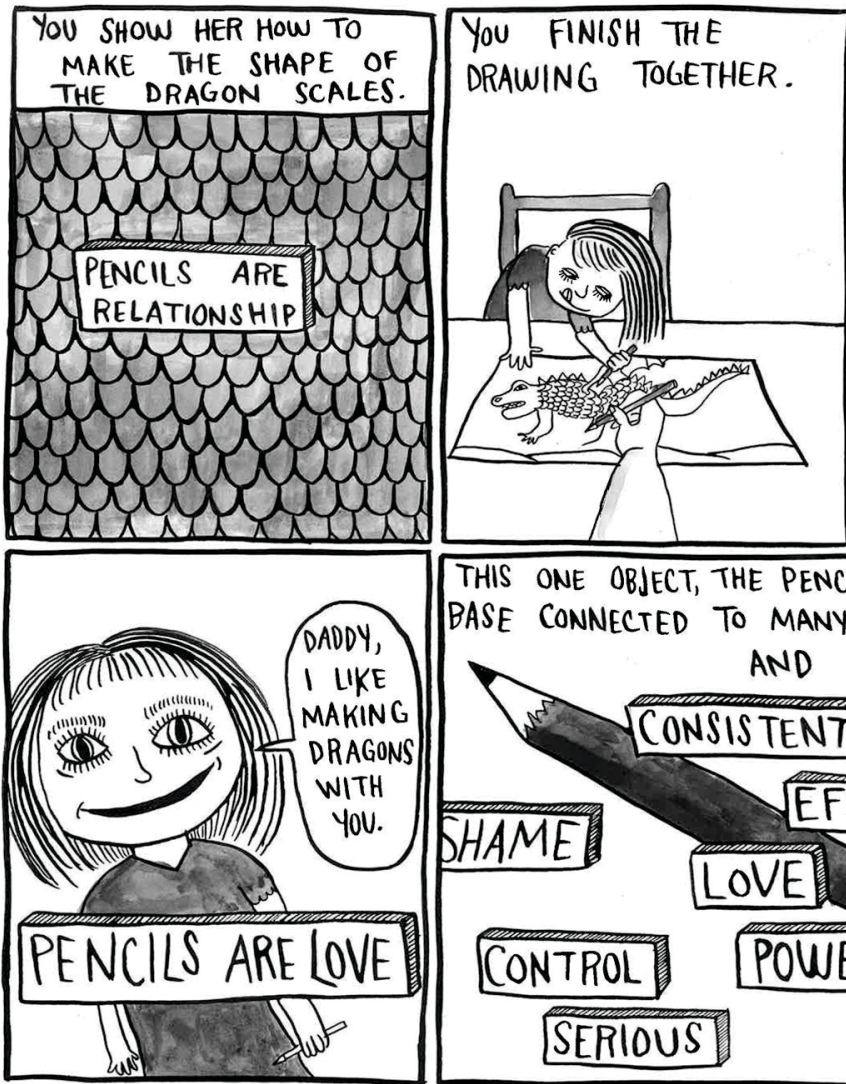
LOOK AT WHAT YOU ACCOMPLISHED!

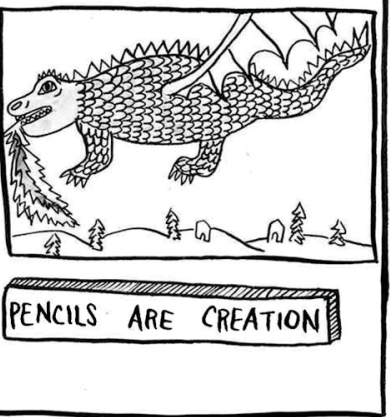

THIS ONE OBJECT, THE PENCIL, IS NOW THE CONCRETE BASE CONNECTED TO MANY INTANGIBLE EMOTIONS
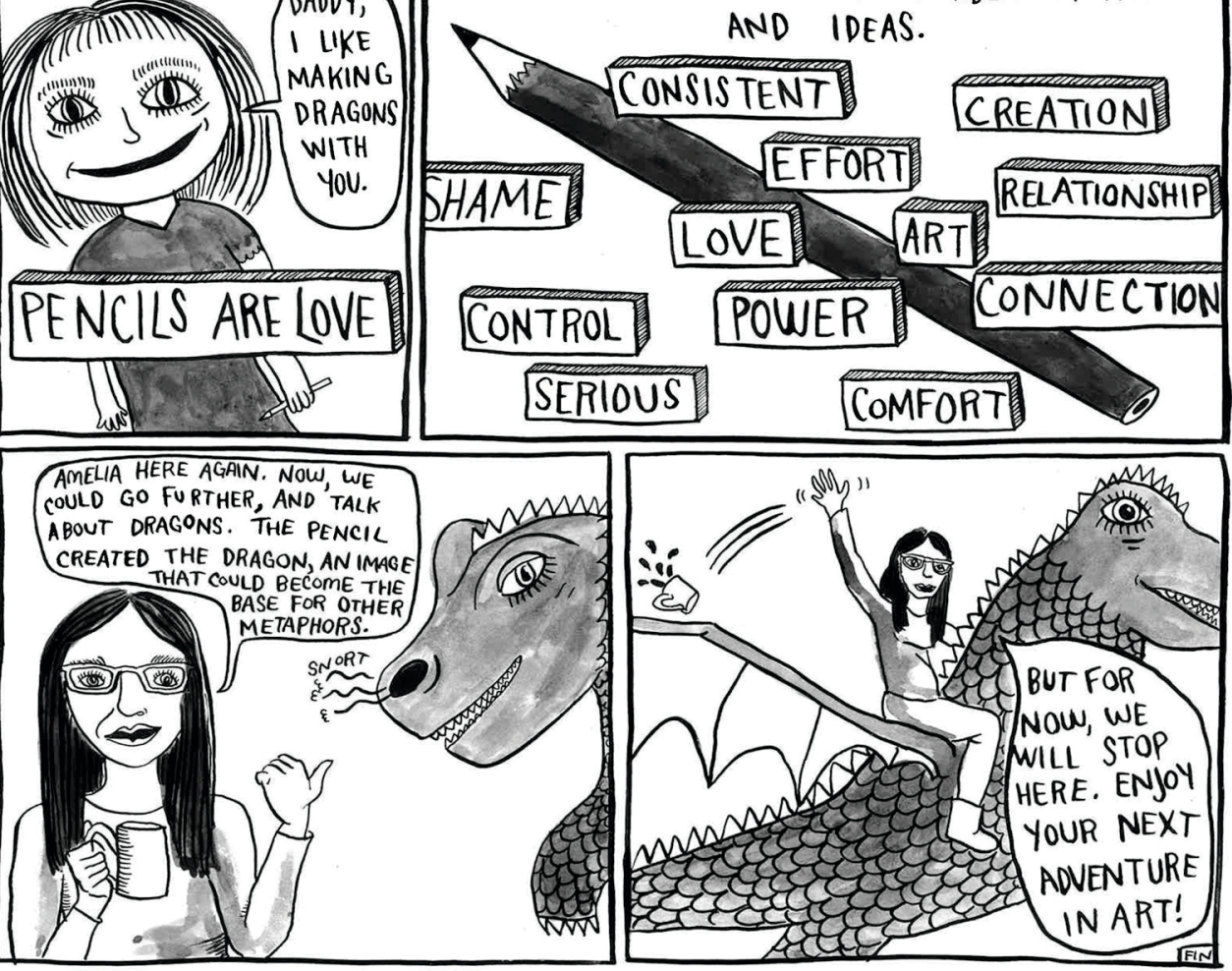